\title{
On the Formation of Leeside Mesolows under Different Froude Number Flow Regime in TAMEX
}

\author{
Chung-Chieh WANG \\ Department of Environmental Management, Jin-Wen Institute of Technology, Taiwan, ROC \\ and \\ George Tai-Jen CHEN \\ Department of Atmospheric Sciences, National Taiwan University, Taiwan, ROC \\ (Manuscript received 3 July 2001, in revised form 31 December 2002)
}

\begin{abstract}
During the Mei-Yu season, when the surface front approaches and pre-frontal southwesterly flow intensifies, shallow and short-lived mesolows often form to the southeast of Taiwan on the leeside of the Central Mountain Range (CMR). Although they develop under similar synoptic settings, cases observed during the Taiwan Area Mesoscale Experiment (TAMEX) in 1987 still exhibited some case-to-case variations, particularly in the upstream Froude number $(F r)$ and the amount of windward-side precipitation. The present study selects two cases with more contrasting mesoscale characteristics for detailed examination, and differences found in their flow structure and associated features are discussed and compared with theoretical aspects.

Results indicate that as long as $\mathrm{Fr}$ exceeds a certain value, two possible scenarios associated with relatively higher and lower $\mathrm{Fr}$ values can lead to formation of leeside mesolow through slightly different combination of processes. The case with a larger $F r(>0.5)$ on June 7-8 had a flow structure relatively more in favor of the "flow-over" regime under stronger prevailing winds. The airflow produced a large amount of precipitation at the windward side then sunk at the leeside together with parcels from higher levels. The adiabatic warming led to formation of the mesolow, which had no corresponding mesovortex most of the time with a higher Rossby number $(R o \approx 2)$, but small and localized vortices independent from the low might appear at other favorable spots near the terrain.

The second TAMEX case (June 2) had smaller $\operatorname{Fr}(<0.2)$ and $R o(<1)$ values. Due to the stronger Coriolis deflection and upstream blocking effect, the flow showed more characteristics of the "flowaround" regime. Only a relatively shallow layer below the crest of the CMR was able to climb over, and subsequently nearly no precipitation was produced. However, the stronger blocking allowed air parcels above the mountain crest to sink directly at the lee for greater depths as a transient response, and to produce mesolow at comparable strength even without the contribution from latent heat release. In this scenario with smaller $R o$, the low possessed a closed circulation for longer periods during its life span.

Two schematic illustrations are presented to depict the major processes found in these two mesolow cases, which show general agreement with theoretical aspects and exemplify variations in flow structure
\end{abstract}

Corresponding author: George Tai-Jen Chen, Department of Atmospheric Sciences, National Taiwan University, 61, Ln 144, Sec. 4, Keelung Rd., Taipei, Taiwan 10772, ROC.

E-mail: george@george2.as.ntu.edu.tw

(C) 2003, Meteorological Society of Japan 
under slightly different $F r$ and $R o$ values in the real atmosphere from an observational standpoint. Cases with characteristics in between the two scenarios are also expected.

\section{Introduction}

One of the mesoscale phenomena observed near Taiwan and its adjacent area during the Mei-Yu season from May to June is the mesolow. Although mesolows also develop along the northwestern and western coast of Taiwan, they appear most frequently to the southeast of Taiwan at the leeside of the Central Mountain Range (CMR), when the surface Mei-Yu front approaches and the pre-frontal southwesterly flow intensifies (Fig. 1, Chen 1978). Mesolows have a horizontal scale of about $150-200 \mathrm{~km}$, and are shallow, usually below $1500 \mathrm{~m}$, and once formed they tend to be stationary or move slowly. Their averaged life span is about $12 \mathrm{~h}$, and the sea-level pressure (SLP) perturbation is a few hundred Pascals (Chen 1990, 1992a). A review on Taiwan mesolows can be found in Chen (1995).

The geography, elongated shape and steep terrain of Taiwan have made the island an

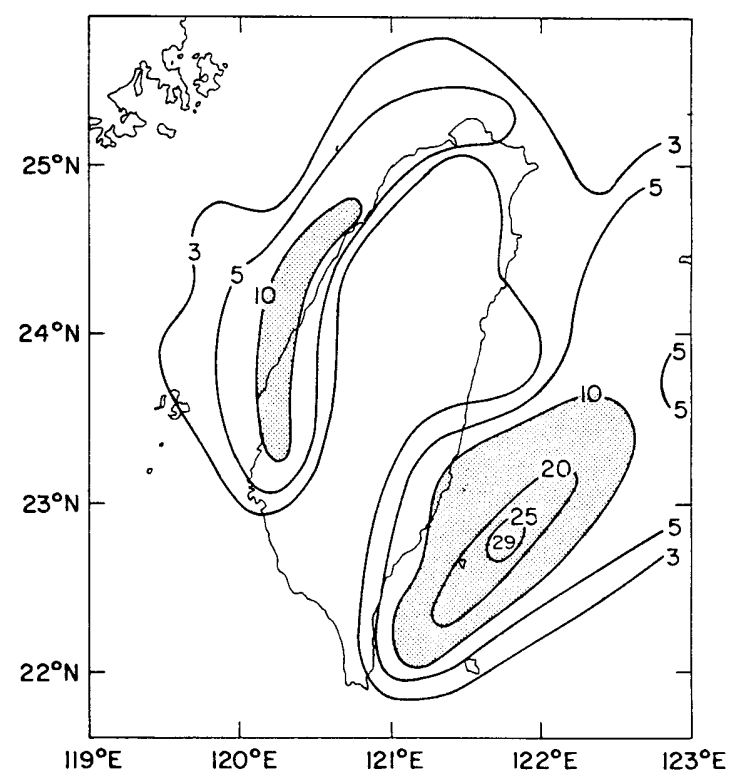

Fig. 1. Frequency distribution of mesolow appearance near Taiwan (inside $0.5^{\circ}$ latitude $\times 0.5^{\circ}$ longitude boxes) during the Mei-Yu season (May 15 to June 18) of six years from 1972 to 1977 (adopted from Chen 1978). ideal target for studying mesolows and phenomena related to lee cyclogenesis. The understanding has been substantially improved since the Taiwan Area Mesoscale Experiment (TAMEX) held in May to June 1987 (Kuo and Chen 1990). The case that occurred on May 17 during the second Intensive Observing Period (IOP-2), in particular, was studied in detail by Lin et al. (1992) and Sun and Chern (1993) through model simulations. Both their research and other observational studies have suggested that the primary mechanism for the formation and maintenance of mesolows to the southeast of Taiwan is the warming induced by adiabatic subsidence at the leeside (Chen 1992b, 1993; Sun et al. 1991). Except the IOP-2 case, Chen (1991) identified eight other mesolow cases in TAMEX, some during IOPs while others not. They occurred under similar synoptic settings, but the mesoscale conditions were not all alike and exhibited a certain extent of case-tocase variation, particularly in the amount of windward-side precipitation, and the upstream Froude number $(F r=U / N h$, where $U$ is the wind speed perpendicular to the mountain, $h$ is terrain height, and $N$ is the Brunt-Väisälä frequency defined as $N^{2}=(g / \theta)(d \theta / d z)$ where $\theta$ is potential temperature), among other factors. Obviously, in cases with different rainfall amount, moist processes (i.e., latent heat release) must have contributed differently as a source of higher $\theta$ values at the lee. In cases with different $F r$ values, there also must be variations in flow structure. How these details manifest in real cases, however, are not well known, and remain to be further explored. The aim of the current paper, therefore, is to document and compare leeside mesolows over the southeast of Taiwan under similar synopticscale but different mesoscale upstream conditions, especially from an observational standpoint. The observed differences in flow structure and relevant features associated with the low are subsequently discussed from a theoretical perspective.

It is also found that a mesolow to the southeast of Taiwan may, or may not, accompany a well-defined mesovortex in the wind field. 
This suggests a different primary, and possibly much more complicated mechanism(s) controlling the development and evolution of the mesovortex at the leeside (e.g., Lin et al. 1992; Chen 1992b; Wang and Chen 2002). Although the detailed mechanism for the formation of leeside vortices is not the focus of this paper, their possible relations to the mesolow will also be discussed to some extent.

In section 2 , the observational data employed and the methodology of analysis is described. Some general characteristics of mesolows observed in TAMEX and their variability are first discussed in section 3. Then, two individual cases with contrasting mesoscale conditions (in rainfall amount and $\mathrm{Fr}$ in particular) are chosen for further detailed examination, and results are presented in sections 4 and 5, respectively. Section 6 discusses the differences found between cases exemplified in previous sections, mainly from a theoretical perspective. Finally, section 7 summarizes the major findings of the study.

\section{Data and analysis}

Data employed in the present study include East-Asia weather maps at mandatory levels, hourly TAMEX original surface station plots (Wang 1990), hourly surface station and raingauge network data in the Taiwan area (including ship observations), and 3-hourly (IOP) or 6-hourly (non-IOP) upper air sounding and pilot-balloon winds during the period of selected mesolow cases. The locations of the TAMEX rawinsonde and pilot-balloon network and some relevant surface stations, as well as the terrain of Taiwan are shown in Fig. 2.

The definitions of mesolow, mesovortex, and mesocyclone follow those by Chen (1991, $1992 b)$. That is, a mesolow is considered pres-

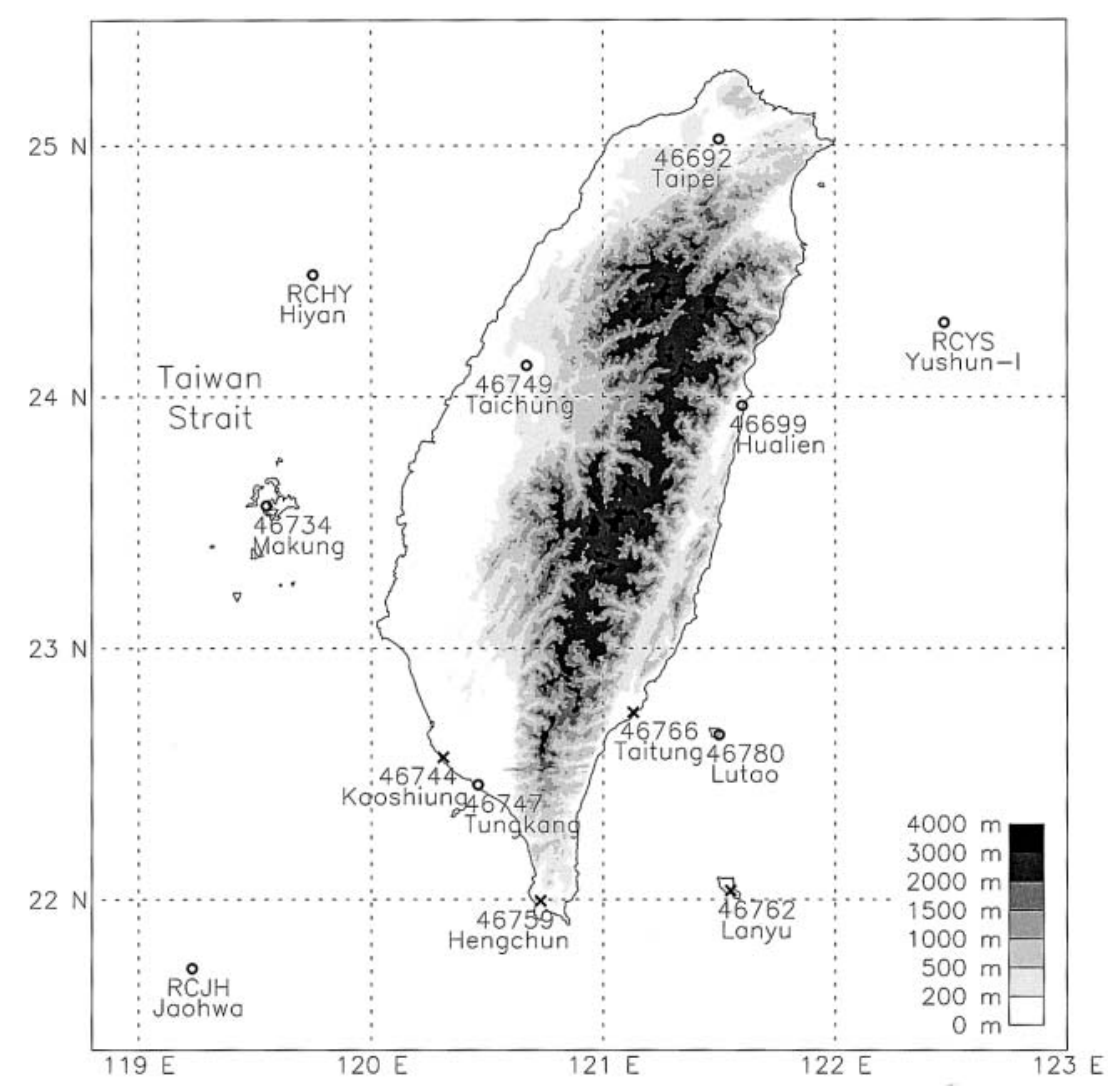

Fig. 2. Terrain of Taiwan and locations of rawinsonde stations (circle) during the Taiwan Area Mesoscale Experiment (TAMEX) in 1987. Surface stations discussed in the text are indicated by cross signs. 
ent when the difference in SLP, with the mean May-June diurnal cycle removed, between Kaoshiung (46744) in southwestern Taiwan and Taitung (46766) in southeastern Taiwan (Fig. 2) is greater than $1.5 \mathrm{hPa}$ for at least 6 hours. A mesovortex is considered present when a closed circulation can be analyzed in the wind field, while a mesocyclone is defined if both mesolow and mesovortex exist and their centers are collocated. When identified, a mesolow case is further classified into three life stages based on Kaoshiung minus Taitung SLP difference: intensification, mature, and weakening stages. The intensification stage covers the period of rising SLP difference (must be positive) until one hour before reaching the maximum (or significant decrease in positive tendency); the mature stage runs from an hour before the peak of the SLP difference until it significantly decreases; and finally the weakening stage lasts until the decreasing tendency of SLP difference diminishes (Chen 1991).

Upstream $\mathrm{Fr}$ values were calculated using sounding data at Makung and ship Jaohwa (RCJH) between 750 and $1500 \mathrm{~m}$, with a mountain height of $1800 \mathrm{~m}$ in southern Taiwan near $22.5^{\circ} \mathrm{N}$ (cf., Fig. 2). Lalas and Einaudi (1974) and Durran and Klemp (1982) provided methods to adjust $N$ to account for latent heat release when saturation is achieved, and our calculation was based on the latter method such that

$$
\begin{aligned}
N_{m}^{2}=g & \left\{\frac{1+\left(L q_{s} / R T\right)}{1+\left(\varepsilon L^{2} q_{s} / C_{p} R T^{2}\right)}\right. \\
& \left.\times\left(\frac{d \ln \theta}{d z}+\frac{L}{C_{p} T} \frac{d q_{s}}{d z}\right)-\frac{d q_{w}}{d z}\right\},
\end{aligned}
$$

where $\varepsilon=0.622, q_{s}$ is the saturation mixing ratio, $q_{w}$ is the total water mixing ratio (vapor and liquid), while meanings of other symbols follow meteorological convention.

For the two cases selected, mesoscale analyses of SLP at $1 \mathrm{hPa}$ interval (or $0.5 \mathrm{hPa}$ interval as needed), surface streamline, and rainfall distribution were carried out. Time-height cross-sections at Makung (46734), Tungkang (46747) and Lutao (46780, Fig. 2) were constructed for meteorological parameters of interest to examine the evolution at windward side and leeside. For the calculation of vertical velocity $(\omega)$ at Tungkang and Lutao (section
$6 \mathrm{~b})$, the thermodynamic method in natural coordinates was used so that

$$
\omega \approx\left(V_{s} \frac{\partial T}{\partial s}+\frac{\partial T}{\partial t}\right) /\left(\frac{\alpha}{C_{p}}-\frac{\partial T}{\partial p}\right),
$$

where $\alpha$ is the specific volume, and $\alpha / C_{p}-\partial T / \partial p$ in the denominator is often referred to as the stability factor $(\sigma)$. The calculations were performed at the 850 -hPa level for synoptic times (0000 and 1200 UTC) since information at stations nearby were also needed to estimate the horizontal temperature advection.

\section{Characteristics of mesolows observed in TAMEX}

Chen (1991, 1992b) identified eight mesolow cases to the southeast of Taiwan between May 21 and June 29 during TAMEX in 1987. Based on TAMEX operation summary (Wu and Chen 1987), there was a total of 10 times of Mei-Yu front passages over Taiwan during the 1987 Mei-Yu season, on May 3, 5-6, 13-14, 17, 23, and 27-28, and June $2-3,8,15-16$, and 24-25, while the front remained stationary to the north of Taiwan on 20-23 June. Figure 3 shows the time series of Kaoshiung minus Taitung SLP (DPND744) and life stages of the eight cases, all occurred when the Mei-Yu front approached (or was near) northern Taiwan and pre-frontal flow intensified, under more or less similar synoptic setting. Conversely, most frontal passages (between May 21 and June 29) also led to mesolow formation, with the only exception on June 15-16, when the southwesterly flow was too weak (Wu and Chen 1987). The life span of these cases ranged from $11 \mathrm{~h}$ (case 2) to $17.5 \mathrm{~h}$ (case 5), while the largest Kaoshiung-Taitung SLP ranged from 2.3 to $4.8 \mathrm{hPa}$ in the mature stage. The SLP difference between two stations farther north near $24^{\circ} \mathrm{N}$ (Taichung and Hualien) is also plotted in Fig. 3 as line DPND749 for comparison. Although DPND749 had similar trends, the pressure deficit was mostly smaller.

Beside under similar synoptic settings, these eight mesolows formed at nearly the same location, with their warm and dry properties most significant in mature and weakening stages (Chen 1992b), suggesting the dominant role of adiabatic subsidence in their formation. Some more subtle differences in environmental conditions, however, are quite evident among 

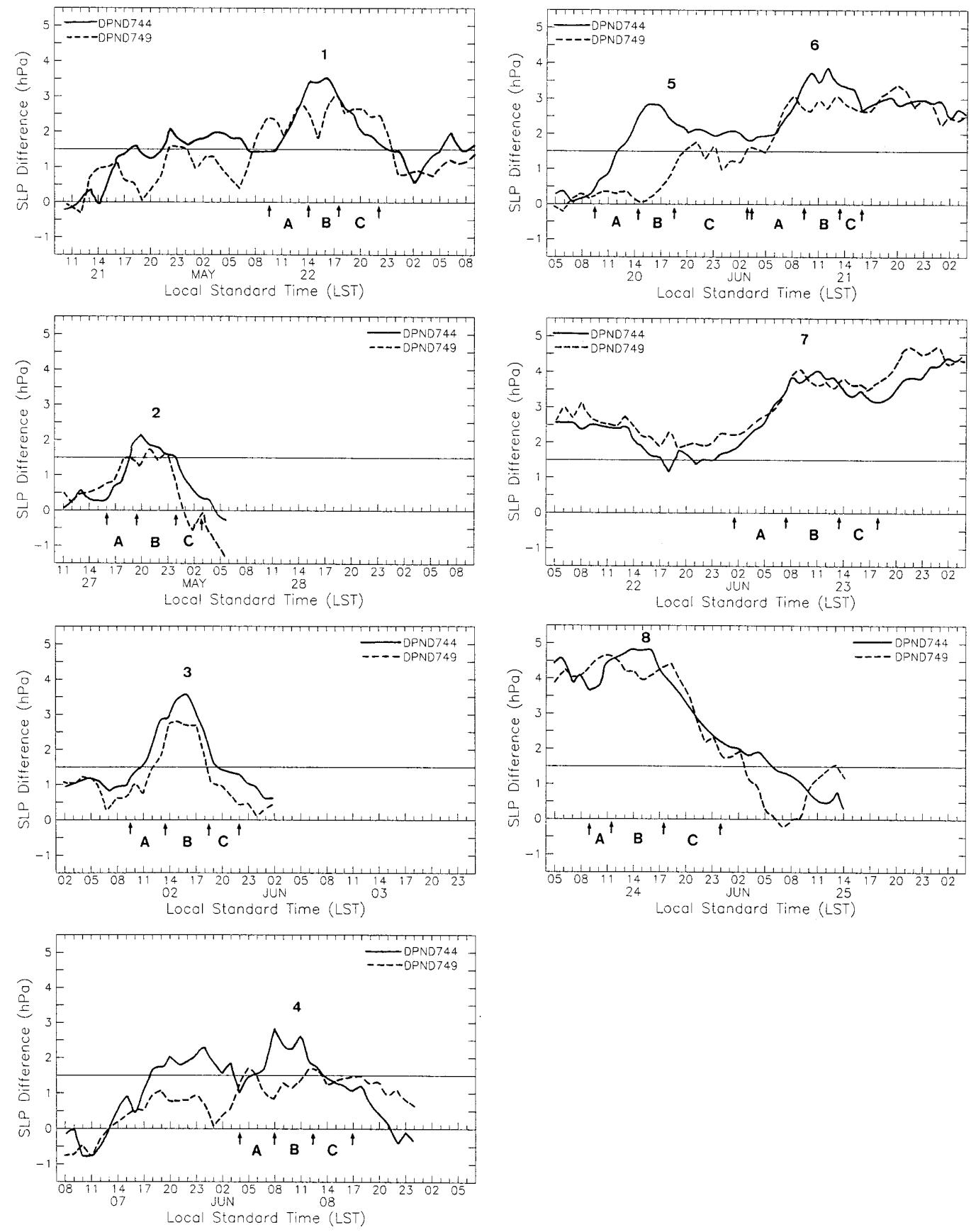

Fig. 3. Time series of sea level pressure (SLP) difference between windward side and lee side of southern Central Mountain Range (CMR) in Taiwan, and eight mesolow cases in May-June, 1987 and their life stages identified by Chen (1991). DPND744 represents Kaoshiung minus Taitung SLP, and DPND749 represents Taichung minus Hualien SLP, both with mean May-June diurnal SLP variation removed. Letters "A", "B", and "C" denote intensification, mature, and weakening stages, respectively. 
Table 1. Upstream Froude number (Fr) computed using Makung and Jaohwa (RCJH) sounding data at 750-1500 $\mathrm{m}$ and a terrain height of $1800 \mathrm{~m}$ during the intensification (A), mature (B), and weakening stages $(\mathrm{C})$ of eight selected mesolow cases. Some values are missing due to insufficient data for calculation.

\begin{tabular}{lcccccccc}
\hline & \multicolumn{3}{c}{ Life stages } & & & \multicolumn{3}{c}{ Life stages } \\
\cline { 2 - 4 } \cline { 8 - 9 } Case & $\mathrm{A}$ & $\mathrm{B}$ & $\mathrm{C}$ & & Case & $\mathrm{A}$ & $\mathrm{B}$ & $\mathrm{C}$ \\
\hline \hline 1 & 0.28 & 0.26 & 0.14 & & 5 & - & - & 0.01 \\
2 & 0.29 & 0.29 & 0.27 & & 6 & 0.04 & - & - \\
3 & 0.17 & 0.08 & 0.20 & & 7 & - & 0.30 & 0.30 \\
4 & 0.25 & 0.51 & 0.61 & & 8 & - & - & 0.46 \\
\hline
\end{tabular}

Table 2. Prevailing wind direction and speed at Tungkang (46744) in the intensification stage, and orientation of mesoscale high-low couplet in the mature stage of eight selected mesolow cases.

\begin{tabular}{|c|c|c|c|c|c|}
\hline Case & $\begin{array}{l}\text { Prevailing } \\
\text { wind }\end{array}$ & $\begin{array}{l}\text { High-low } \\
\text { orientation }\end{array}$ & Case & $\begin{array}{l}\text { Prevailing } \\
\text { wind }\end{array}$ & $\begin{array}{c}\text { High-low } \\
\text { orientation }\end{array}$ \\
\hline 1 & WSW, $15 \mathrm{kts}$ & WNW-ESE & 5 & SSW, $18 \mathrm{kts}$ & SW-NE \\
\hline 2 & $\mathrm{NW}, 10 \mathrm{kts}$ & NW-SE & 6 & WSW, 17 kts & WNW-ESE \\
\hline 3 & $\mathrm{~W}, 12 \mathrm{kts}$ & NNW-SSE & 7 & WNW, 19 kts & NW-SE \\
\hline 4 & $\mathrm{~W}, 20 \mathrm{kts}$ & WNW-ESE & 8 & WNW, $25 \mathrm{kts}$ & NW-SE \\
\hline
\end{tabular}

cases, such as the upstream Froude number. Table 1 shows the $F r$ values in different life stages of the cases, calculated using the method described in section 2. Some cases had an Fr value near or even greater than 0.5 at some stages, while others might have one below 0.2 . However, all these values fall within the range of $F r<1$, where upstream blocking and lee vortices form through linear theory and/or tilting of baroclinically-induced vorticity (Smith 1982, 1989; Smolarkiewicz and Rotunno 1989; Rotunno et al. 1999). An additional controlling parameter of the flow structure is the Rossby number $(R o=U / f L$, where $f$ is the Coriolis parameter and $L$ is the characteristic width of the terrain), which measures the importance of the Coriolis effect. For a fixed mountain, $R o$ is proportional to $F r$ under constant $N$, and in the case of CMR where $N \approx 0.01 \mathrm{~s}^{-1}$ and $L \approx$ $70 \mathrm{~km}, R o$ would be roughly 4.3 times the value of Fr. Thus, Ro ranges from greater than 2 to less than 0.5 among our cases, and the Coriolis effect is small in general but not negligible, especially when $R o$ is smaller.

The amount of total precipitation along the windward slope of the CMR over southwestern Taiwan also varied among cases, some substantially exceeding heavy rainfall criteria (cases 4, 6, and 7), while others had only a moderate amount (cases 5 and 8) or nearly no precipitation (cases 1, 2, and 3, Chen 1991). Since adiabatic warming is responsible for mesolow formation, the higher $\theta$ value at the leeside must come from either of the two sources: 1) sinking of air parcels originally at a higher elevation at the windward side; and, 2) latent heat release if condensation is achieved during forced uplift. For cases with a different total rainfall amount, these two sources must have different relative importance in contributing toward the leeside warming.

The impinging angle of prevailing flow, which affects the value of $\mathrm{Fr}$, also showed considerable case-to-case variation. Table 2 presents the averaged 1000-1500 m flow direction/ speed at Tungkang in the intensification stage, and mesolows formed under wind directions varying from south-southwest to northwest. The orientation of mesoscale high-low couplets clearly shows some dependency on the direction of prevailing flow, and tends to shift from southwest-northeast to northwest-southeast when the flow turns from south-southwesterly to northwesterly. 
Earlier studies have also shown that a mesolow may or may not be associated with a closed vortex circulation in the wind field (e.g., Lin et al. 1992; Chen 1992b, 1995). With a combined life span of $116 \mathrm{~h}$, the eight cases in TAMEX were analyzed as a mesocyclone for a total of $63 \mathrm{~h}$, while they possessed only cyclonically curved flow in the remaining $53 \mathrm{~h}$. In the weakening stage of four cases, the surface Mei$\mathrm{Yu}$ front approached southeast Taiwan and the low transformed into a migratory cyclone along the front, for a total of $17 \mathrm{~h}$. Hence, without the influence of the front, eight leeside mesolows exhibited closed circulation in 46 out of 99 hours, or $46.5 \%$ of the time. Therefore, it is not uncommon for a mesolow to develop to the southeast of Taiwan without an associated vortex in the Mei-Yu season.

Although one of the focal points of the present paper is on the role of dry versus moist processes in raising $\theta$ values at the lee, we have chosen to use $\mathrm{Fr}$ as the basis for classification. The reason is twofold. First, $F r$ represents the overall flow structure of the cases, while precipitation does not carry similar dynamical meaning. Second, $\mathrm{Fr}$ is also linked to rainfall amount since its magnitude controls the uplifting along the windward slope. Therefore, the eight mesolow cases were grouped into two types, based on $F r$ values in Table 1, and the prevailing wind speed and impinging angle in Table 2 were also used when $F r$ is unavailable. Type L cases are those with larger $F r$, including cases 4,7 , and 8 , which also had greater amount of precipitation at the windward side. Type $\mathrm{S}$ cases are those with smaller $\mathrm{Fr}$ and less rainfall, such as cases 1,3 , and 5 . Case 2 can be considered in between the two types, while case 6 was left unclassified due to insufficient information. Two typical cases, one from each type, were chosen for detailed examination and comparison.

The type L case selected is the one occurred on June 7-8 during IOP-8 (case 4 in Tables 1 and 2), for its $F r$ values were the largest among all cases and heavy precipitation fell along the

Table 3. Data availability at key rawinsonde and pibal stations during two mesolow cases selected in this study. Solid circles represent available data (see Fig. 2 for station locations).

\begin{tabular}{|c|c|c|c|c|c|c|c|c|c|c|c|}
\hline \multirow[t]{2}{*}{ Case } & \multirow[t]{2}{*}{ Observation } & \multirow[t]{2}{*}{ Station } & \multicolumn{9}{|c|}{ Date and time (UTC) } \\
\hline & & & $\begin{array}{c}\text { June } 7 \\
1500\end{array}$ & 1800 & 2100 & $\begin{array}{c}\text { June } 8 \\
0000\end{array}$ & 0300 & 0600 & 0900 & 1200 & 1500 \\
\hline $\begin{array}{l}\text { Type L } \\
\text { (Case L) }\end{array}$ & $\begin{array}{l}\text { Rawinsonde } \\
\text { Pibal-wind }\end{array}$ & $\begin{array}{l}46734 \\
46747 \\
46780 \\
\text { RCJH } \\
\text { RCHY } \\
\text { RCYS } \\
46743 \\
46746 \\
46750\end{array}$ & $\begin{array}{l}\bullet \\
\bullet \\
\bullet \\
\bullet \\
\bullet \\
\bullet \\
\bullet \\
\bullet\end{array}$ & $\begin{array}{l}\bullet \\
\bullet \\
\bullet \\
\bullet \\
\bullet \\
\bullet \\
\bullet \\
\bullet \\
\bullet\end{array}$ & • & $\begin{array}{l}\cdot \\
\bullet \\
\bullet \\
\bullet \\
\bullet \\
\bullet \\
\bullet \\
\bullet \\
\bullet\end{array}$ & $\begin{array}{l}\bullet \\
\bullet \\
\bullet \\
\bullet\end{array}$ & $\begin{array}{l}\bullet \\
\bullet \\
\bullet \\
\bullet\end{array}$ & $\begin{array}{l}\bullet \\
\bullet \\
\bullet\end{array}$ & $\begin{array}{l}\bullet \\
\bullet \\
\bullet \\
\bullet \\
\bullet \\
\bullet \\
\bullet\end{array}$ & $\begin{array}{l}\bullet \\
\bullet \\
\bullet\end{array}$ \\
\hline & & & $\begin{array}{c}\text { June } 1 \\
1800\end{array}$ & 2100 & $\begin{array}{c}\text { June } 2 \\
0000\end{array}$ & 0300 & 0600 & 0900 & 1200 & 1500 & 1800 \\
\hline $\begin{array}{l}\text { Type S } \\
\text { (Case S) }\end{array}$ & Rawinsonde & $\begin{array}{l}46734 \\
46747 \\
46780 \\
\text { RCJH } \\
\text { RCHY } \\
\text { RCYS } \\
46743 \\
46746 \\
46750\end{array}$ & $\begin{array}{l}\bullet \\
\bullet \\
\bullet \\
\bullet \\
\bullet \\
\bullet \\
\bullet \\
\bullet\end{array}$ & $\begin{array}{l}\bullet \\
\bullet \\
\bullet \\
\bullet \\
\bullet \\
\bullet \\
\bullet \\
\bullet\end{array}$ & $\begin{array}{l}\bullet \\
\bullet \\
\bullet \\
\bullet \\
\bullet \\
\bullet \\
\bullet \\
\bullet \\
\bullet\end{array}$ & & $\begin{array}{l}\bullet \\
\bullet \\
\bullet \\
\bullet \\
\bullet \\
\bullet \\
\bullet \\
\bullet \\
\bullet\end{array}$ & $\begin{array}{l}\bullet \\
\bullet \\
\bullet \\
\bullet \\
\bullet \\
\bullet \\
\bullet \\
\bullet\end{array}$ & $\begin{array}{l}\bullet \\
\bullet \\
\bullet \\
\bullet \\
\bullet \\
\bullet \\
\bullet \\
\bullet\end{array}$ & • & $\begin{array}{l}\bullet \\
\bullet \\
\bullet \\
\bullet \\
\bullet \\
\bullet \\
\bullet \\
\bullet \\
\bullet\end{array}$ \\
\hline
\end{tabular}


windward slope. The type $\mathrm{S}$ case is on June 2 during TAMEX IOP-6 (case 3), and its $F r$ was significantly smaller with nearly no rain produced. The selection was partially based on data availability at several key sounding sites (both cases during IOPs), which is summarized in Table 3. The surface Mei-Yu front approached Taiwan, and a barrier jet formed in both cases due to terrain blocking ( $\mathrm{Li}$ and Chen 1998).

\section{Mesolow case of Type $L$}

\subsection{Synoptic conditions}

The type L case of mesolow (referred as case L hereafter) occurred on June 7-8, 1987 during TAMEX IOP-8 (0600 UTC, June 7 to 0000 UTC, June 9). This case is described in greater detail in Wang and Chen (2002), and therefore will be presented rather briefly here. The synoptic condition at 0000 UTC of June 8 at the beginning of mature stage shows that the surface Mei-Yu front was passing through northern Taiwan, while at $850 \mathrm{hPa}$ the prevailing wind was southwesterly at about $10 \mathrm{~m} \mathrm{~s}^{-1}$ with flow splitting in southwestern Taiwan (Fig. 4).

\subsection{Mesoscale analyses of case evolution}

Figure 5 shows mesoscale analyses of SLP and streamlines in the Taiwan area at selected times during the life span of case L. At 2100 UTC of June 7 in the intensification stage (Fig. 5a), the southwesterly airflow split upstream from the terrain, with one branch to the north and the other around the southern tip of the CMR to the east. An east-west mesohigh-low couplet already existed, with the mesolow center north of Lutao near $22.9^{\circ} \mathrm{N}$. The surface air flew cyclonically through the low without forming a closed circulation, while a mesovortex appeared at the northeast corner of Hengchun Peninsula at southern Taiwan (near $22.4^{\circ} \mathrm{N}$, $120.9^{\circ} \mathrm{E}$ ), about $90 \mathrm{~km}$ to the southwest of the low. The wind speed at Lanyu $\left(22.1^{\circ} \mathrm{N} / 121.5^{\circ} \mathrm{E}\right)$ was about $12 \mathrm{~m} \mathrm{~s}^{-1}$ at this time.

At 0200 UTC of June 8 in the mature stage (Fig. 5b), surface Mei-Yu front broke into two segments while passing northern Taiwan. The upstream prevailing wind increased from 5 to $10 \mathrm{~m} \mathrm{~s}^{-1}$, and wind speed at Lanyu also strengthened to almost $20 \mathrm{~m} \mathrm{~s}^{-1}$. The vortex near Hengchun Peninsula was near $22.6^{\circ} \mathrm{N}$ and remained rather stationary. The mesolow was
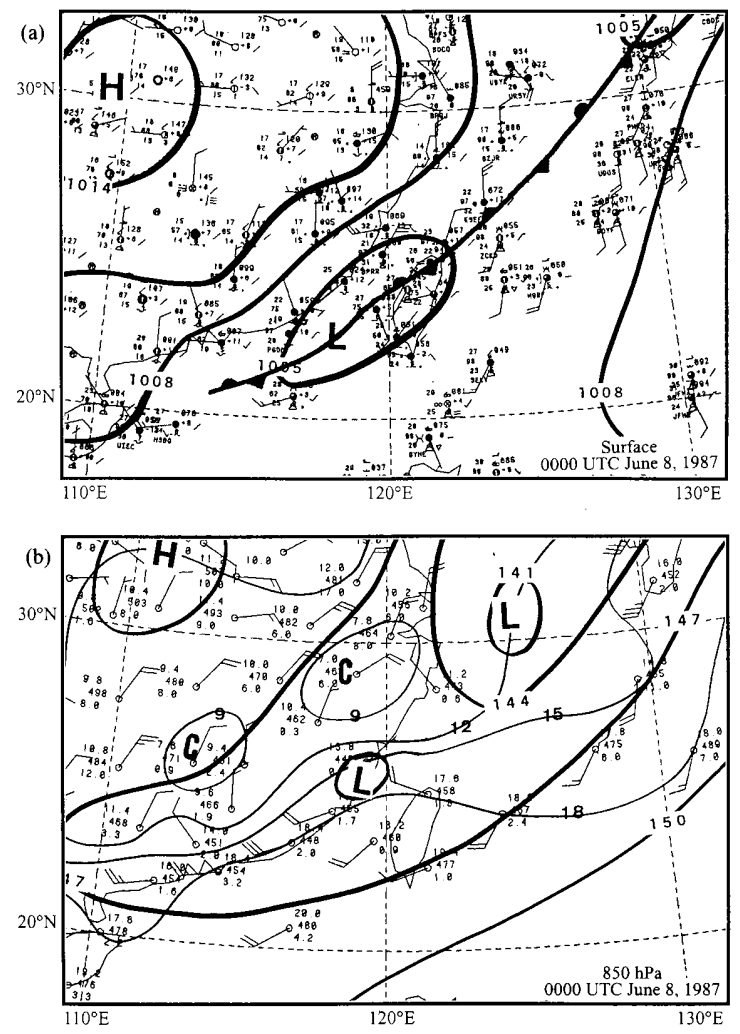

Fig. 4. Synoptic weather maps at (a) sea level, and (b) $850 \mathrm{hPa}$ for $0000 \mathrm{UTC}$, June 8, 1987. Thick solid lines are pressure $(\mathrm{hPa})$ at surface and geopotential height (dam) at $850 \mathrm{hPa}$. Thin lines are isotherms $\left({ }^{\circ} \mathrm{C}\right)$, and station plots follow meteorological convention.

also stationary to the north of Lutao near $23^{\circ} \mathrm{N}$, with cyclonic flow through its center.

In the weakening stage at 0600 UTC (Fig. $5 \mathrm{c}$ ), the eastern segment of the Mei-Yu front had approached the mesolow. The low then merged with the front to form a mesocyclone, and then transformed into a migratory system along the front (not shown). Therefore, the leeside mesolow did not possess a closed circulation during most of its life span in case L, and little adjustment was observed between the low and the vortex to its southwest.

\subsection{Upstream conditions}

In order to determine the layer of upstream air that carries enough kinetic energy to climb over the CMR, a parameter named the local $\mathrm{Fr}$ 

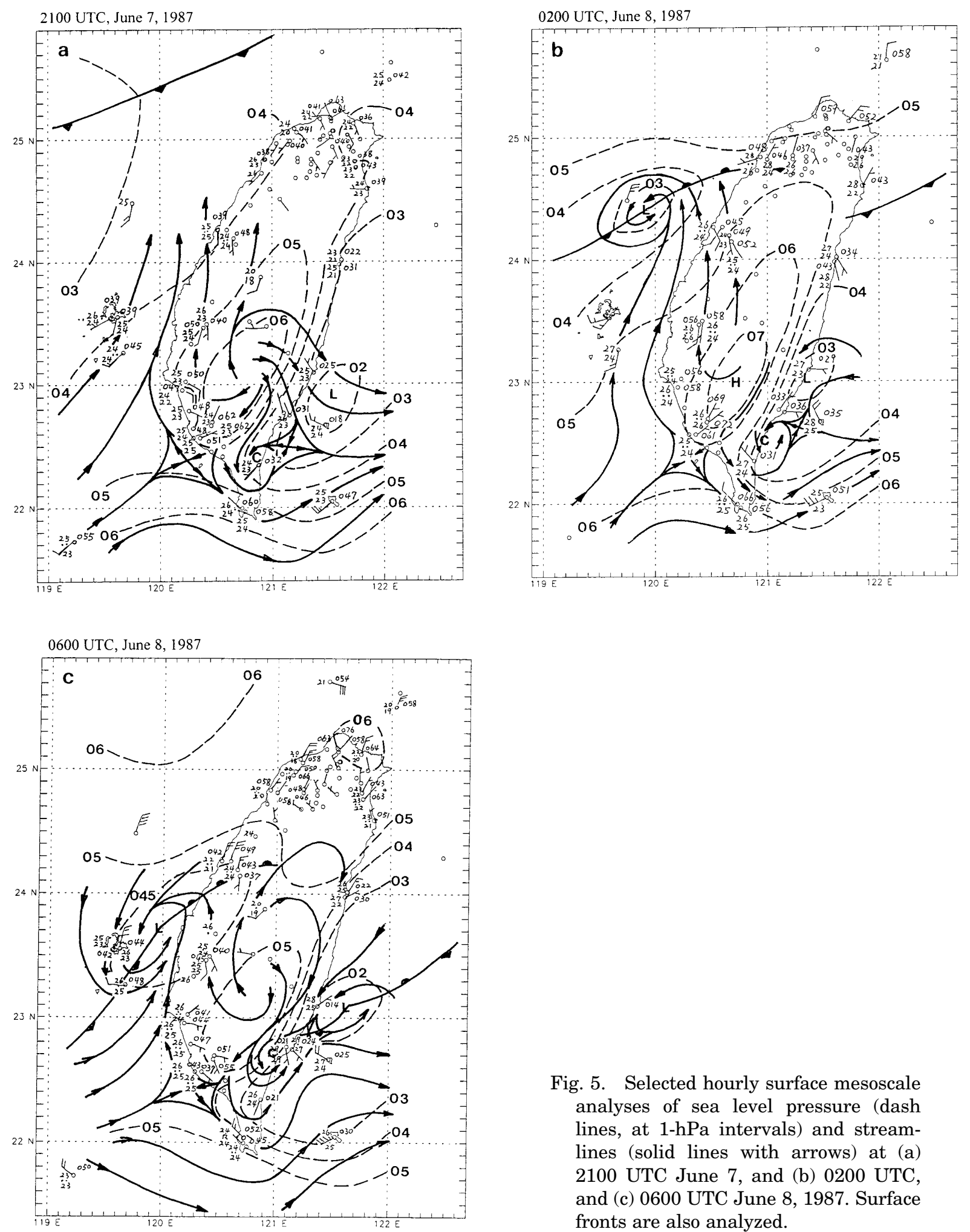

Fig. 5. Selected hourly surface mesoscale analyses of sea level pressure (dash lines, at $1-\mathrm{hPa}$ intervals) and streamlines (solid lines with arrows) at (a) 2100 UTC June 7, and (b) 0200 UTC, and (c) 0600 UTC June 8, 1987. Surface fronts are also analyzed. 


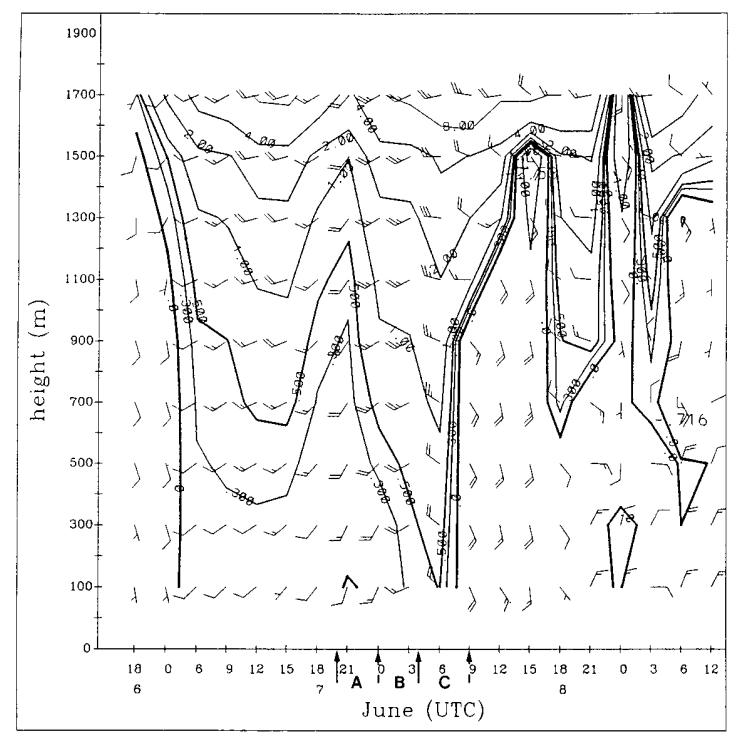

Fig. 6. Time-height cross-section of local Froude number and wind averaged between Makung and research vessel RCJH from 1800 UTC June 6 to 1200 UTC June 9, 1987. Contour line values are $0.0,0.3,0.5,1.0,2.0,4.0$, and 8.0. The letters "A", "B", and "C" denote intensification, mature, and weakening stages of case L, respectively.

is defined, which is calculated in the same way as $F r$, but the relative terrain height is used instead for air parcels at different levels. Therefore, it represents the ratio of the inertial force of the parcel to the buoyancy force, without considering effects of pressure variation (see e.g., Smith 1990; Baines 1995 for further discussion). Using sounding data averaged between Makung and Jaohwa, the local $F r$ was evaluated for parcels at 100 to $1700 \mathrm{~m}$ at intervals of $200 \mathrm{~m}$, and its time-height cross-section for a three-day period covering case $\mathrm{L}$ is shown in Fig. 6. Mainly due to a relatively lower obstacle to overcome at higher levels, the local $\mathrm{Fr}$ increased with height, and it also increased with time from 2100 UTC of June 7 to 0600 UTC of June 8. The low level winds were mostly from west-southwest turning westnorthwest at about $12 \mathrm{~m} \mathrm{~s}^{-1}$, and shifted to northeasterly after the frontal passage. The local $F r=1.0$ contour line lowered in elevation with time, from about $1500 \mathrm{~m}$ in the intensification stage to $950 \mathrm{~m}$ in the mature stage, and further to $600 \mathrm{~m}$ in the weakening stage. Similarly, the local $F r=0.5$ contour also became lower, at about 1230,500 , and $100 \mathrm{~m}$ in the three stages, respectively (Fig. 6). Since air parcels with local $F r>1.0$ is usually considered to carry sufficient kinetic energy to climb over the obstacle, while those with local $F r<0.5$ tend to be blocked, Fig. 6 suggests that a considerable depth of air below the mountaintop level could climb over the CMR, especially in the mature and weakening stages before frontal passage.

Precipitation occurred in all three stages of case $\mathrm{L}$, each with normalized rainfall center(s) in excess of $100 \mathrm{~mm} \mathrm{day}^{-1}$ (Fig. 7). Along the southwestern coast and the windward side of the CMR rainfall was heavier during the mature stage. In the weakening stage, the precipitation was still heavy along the windward slope and in southern Hengchun Peninsula, but tended to be more evenly distributed over the southwestern plain, and hence was at least partly linked to the Mei-Yu front (Fig. 7c). At the lee, no rain was recorded until frontal passage in the weakening stage.

The sounding at Tungkang (46747) was used to construct time-height cross-sections and show evolution of various meteorological parameters at the windward side of case L (Fig. 8). Variables include wind, pressure and temperature anomalies, relative humidity, and potential temperature $(\theta)$. The anomalies are deviations from the time-varying mean of the three stations Makung, Tungkang, and Lutao. Although for the construction of such crosssections a time-independent reference state could be used as the mean to retain information about the general trends at individual sites in the anomalies, the method employed here can better contrast the evolutionary differences in pressure and temperature at opposite sides of the CMR in the same case. It also allows an easy comparison between the two cases. The same method was used to construct pressure and temperature anomalies at Lutao (Fig. 9), as well as those for the type $\mathrm{S}$ case (Figs. 13 and 14). Results at Makung will not be discussed, because it contains only limited information relevant to the question.

Figure 8a shows that the low level westerly winds intensified through the life stages from about 7 to $13-15 \mathrm{~m} \mathrm{~s}^{-1}$ at Tungkang, with 

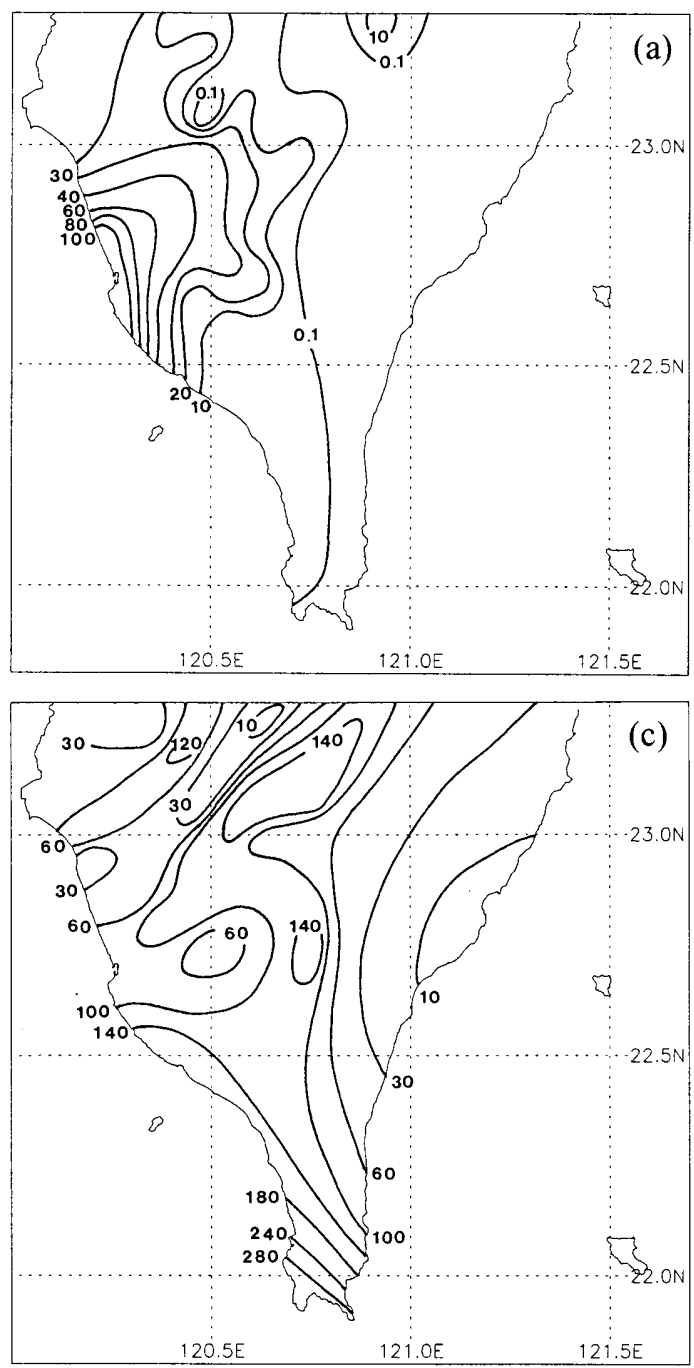

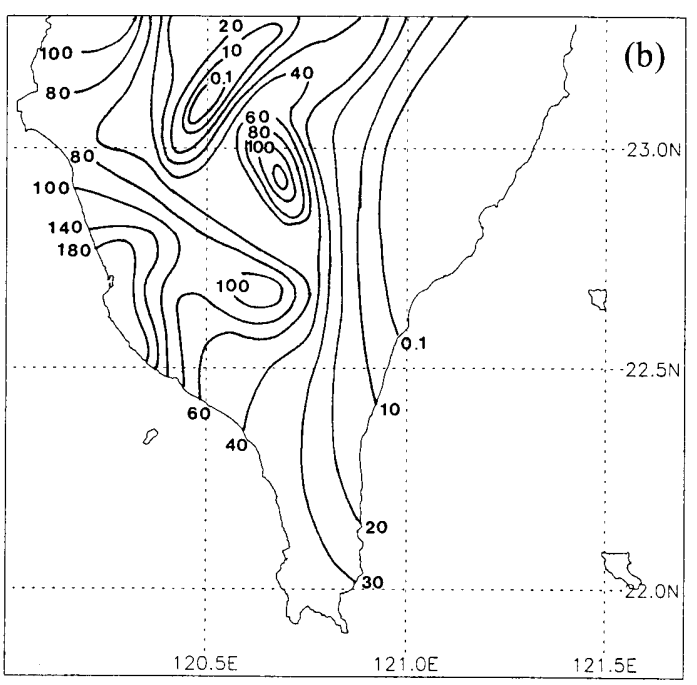

Fig. 7. Distribution of normalized rainfall amount (mm day ${ }^{-1}$ ) during (a) intensification, (b) mature, and (c) weakening stages of case $\mathrm{L}$. stronger winds extending gradually downward. The near-surface wind below $300 \mathrm{~m}$ was northerly or northeasterly, while the surface front passed Tungkang at around 0800 UTC June 8. The pressure anomaly below $2500 \mathrm{~m}$ was negative at the beginning and positive after about 0300 UTC (Fig. 8b), suggesting an overall increase in pressure at Tungkang, compared to Makung and Lutao. The increase was stronger below $1200 \mathrm{~m}$, and produced a maximum of $4.27 \mathrm{hPa}$ at $450 \mathrm{~m}, 0900$ UTC. The temperature anomaly, on the other hand, was negative below about $3000 \mathrm{~m}$, likely caused by the adiabatic cooling at the windward side (Fig. 8c). The positive low-level temperature anomaly after 0700 UTC at Tungkang was likely due to a stronger shading effect from the post-frontal cold air by the CMR.

The relative humidity was high everywhere in the cross-section, with only small variation in values (Fig. 8d). A relative dry center of $90 \%$ $\left(1.9^{\circ} \mathrm{C}\right.$ in dew-point depression) was present at 0000 UTC near $2400 \mathrm{~m}$, and only less than $200 \mathrm{~m}$ of adiabatic uplift would be needed to reach saturation for such high relative humidity. Slopes of isentropic surfaces below $1000 \mathrm{~m}$ indicate slight cooling from 0000 to 0600 UTC and slight warming afterwards (Fig. 8e). A general trend of increasing $\theta$, between 1000 and $2000 \mathrm{~m}$, was also observed. It was likely caused 

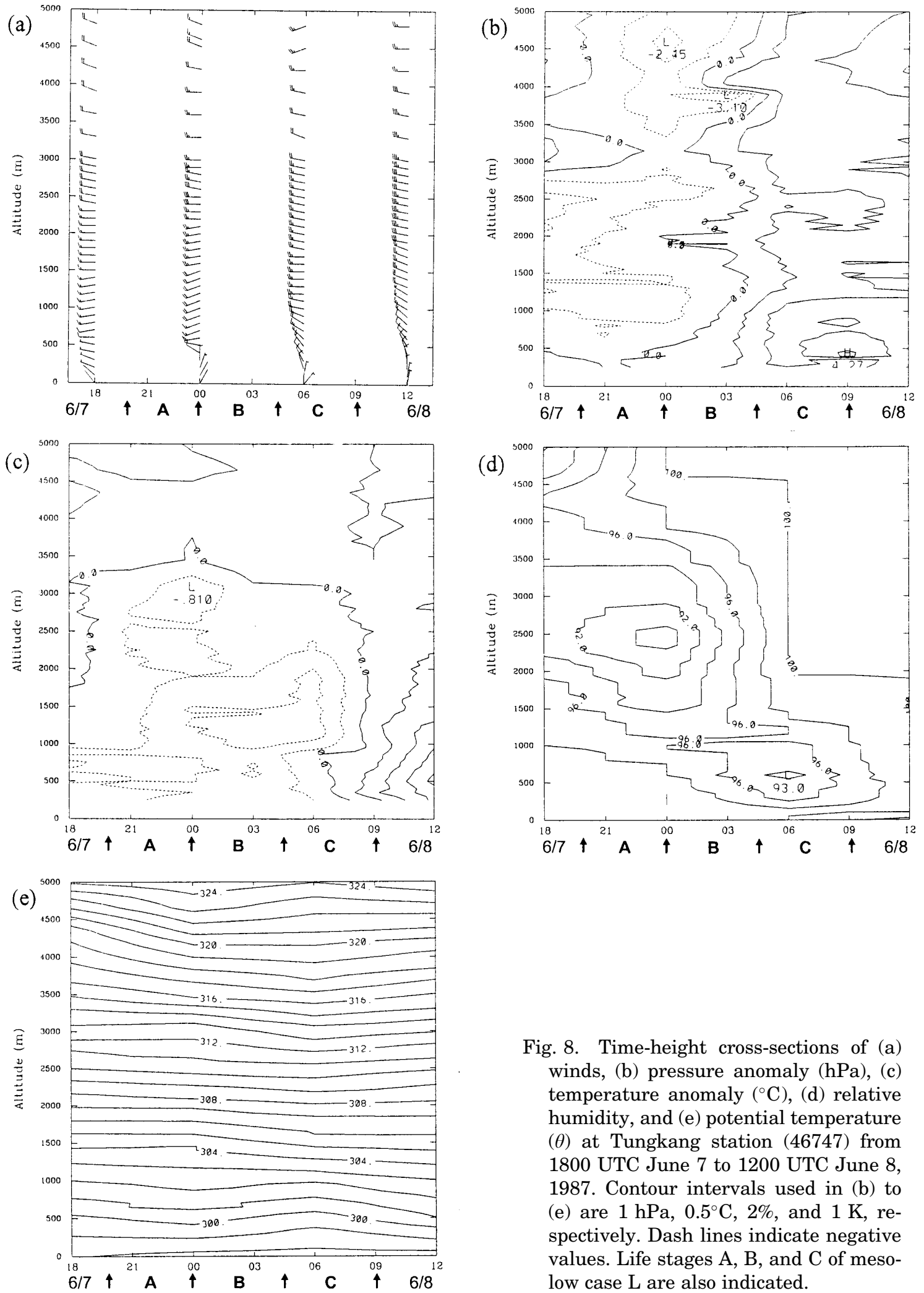

Fig. 8. Time-height cross-sections of (a) winds, (b) pressure anomaly (hPa), (c) temperature anomaly $\left({ }^{\circ} \mathrm{C}\right),(\mathrm{d})$ relative humidity, and (e) potential temperature $(\theta)$ at Tungkang station (46747) from 1800 UTC June 7 to 1200 UTC June 8, 1987. Contour intervals used in (b) to (e) are $1 \mathrm{hPa}, 0.5^{\circ} \mathrm{C}, 2 \%$, and $1 \mathrm{~K}$, respectively. Dash lines indicate negative values. Life stages A, B, and C of mesolow case $\mathrm{L}$ are also indicated. 

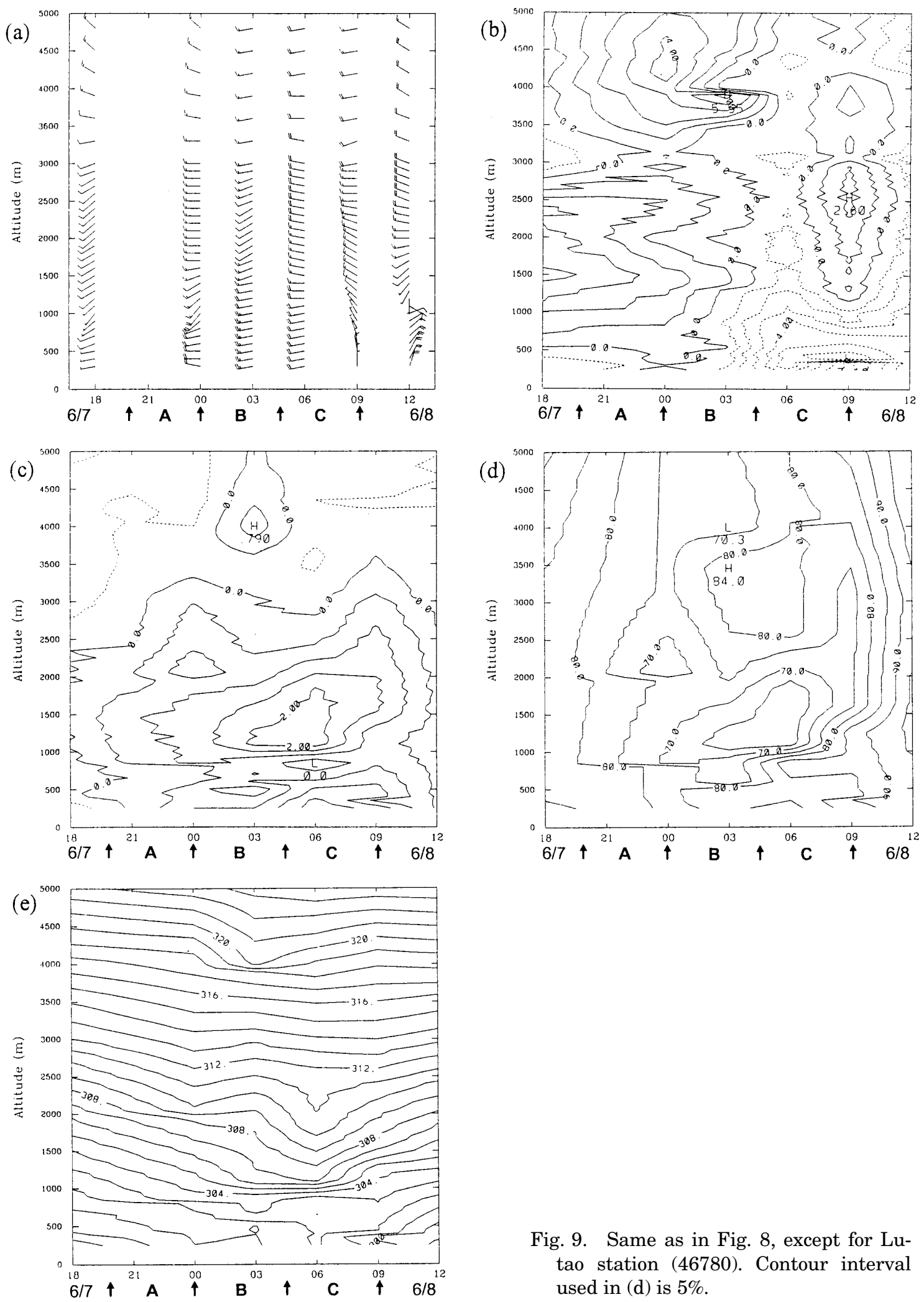

Fig. 9. Same as in Fig. 8, except for Lutao station (46780). Contour interval used in (d) is $5 \%$. 
by latent heat release associated with the rising motion at the windward side.

\subsection{Leeside response}

Time-height cross-sections for the same variables at Lutao are presented in Fig. 9. The southwest/west winds at the leeside were weaker than at the windward side, with a speed less than $10 \mathrm{~m} \mathrm{~s}^{-1}$ except near the surface. The surface Mei-Yu front passed Lutao near 0800 UTC, with northeast flow behind it (Fig. 9a). Opposite to that at Tungkang, the pressure anomaly at Lutao showed an overall decreasing trend from positive to negative values, especially below $1500 \mathrm{~m}$, where a strong negative anomaly center of $-7.1 \mathrm{hPa}$ was reached at $400 \mathrm{~m}, 0900$ UTC (Fig. 9b). The temperature anomaly was positive throughout the life span of case $\mathrm{S}$ below about $3000 \mathrm{~m}$, and the largest anomaly of greater than $2{ }^{\circ} \mathrm{C}$ was achieved between 1000 and $1500 \mathrm{~m}$ at 0600 UTC in the early weakening stage (Fig. 9c).

The relative humidity cross-section (Fig. 9d) shows a clear and steady drying trend at Lutao between 1000 and $2000 \mathrm{~m}$ till 0600 UTC. The dry center had a value less than $65 \%$ (or $7.5^{\circ} \mathrm{C}$ in dew-point depression) near $1500 \mathrm{~m}$. Such a pattern of warming and drying was caused by strong adiabatic subsidence at the leeside of the mountain. In the cross-section of $\theta$ (Fig. 9e), isentropes between 1000 and $2000 \mathrm{~m}$ sloped downward significantly before 0600 UTC and upward afterwards, reflecting the change in strength of subsidence warming before and after frontal passage. The warming near $1300 \mathrm{~m}$ was about $5 \mathrm{~K}$ in $12 \mathrm{~h}$. A stable layer appeared near $1000 \mathrm{~m}$ between 0200 and 0700 UTC (Fig. $9 \mathrm{e}$ ), indicating the bottom of sinking motion. The vertical gradient of equivalent potential temperature $\left(\theta_{e}\right)$ was small (and negative) in the lower troposphere, and increased by about $4 \mathrm{~K}$ at $1300 \mathrm{~m}$ (not shown). Thus, most crosssections at Lutao show distinctly different features from, some quite opposite to, those observed at Tungkang in the lower troposphere during the life span of the first case.

\subsection{Case summary}

In summary, the mesolow case L (June 7-8, 1987) developed when the Mei-Yu front approached Taiwan, and the prevailing westsouthwest winds strengthened, along with an increase in $\mathrm{Fr}$ from below to above 0.5 (Table 1). The low-level flow (with a depth of less than $\sim 1200 \mathrm{~m}$ and decreasing significantly with time) split upstream of the CMR and moved around it, producing low level jets (LLJs) in both northwestern and southern ends of the terrain. The airflow above splitting layer rose and cooled at the windward side, and sunk and warmed at the leeside of CMR, producing a pair of mesoscale high-low pressure couplets at sea level. Heavy precipitation occurred over the southwestern plain and along the windward side of the southern CMR. At the leeside, little precipitation was observed, while the adiabatic warming was evident between 1000 and $2000 \mathrm{~m}$. The stable layer at the bottom of the adiabatic subsidence was located near $1000 \mathrm{~m}$.

The leeside mesolow formed early in the life stage near $22.9^{\circ} \mathrm{N}$, with closed isobars but no closed circulation. The low remained quasistationary until the Mei-Yu front approached, then transformed into a migratory mesocyclone along the front. A localized mesovortex also formed to the southwest of the mesolow in the intensification stage. The two centers were about $90 \mathrm{~km}$ apart, and little adjustment in location was observed between them.

\section{Mesolow case of Type $S$}

\subsection{Synoptic conditions}

The type S mesolow case (case S) occurred on June 2, 1987, six days before the type L case. The TAMEX IOP-6 was carried out within its life span (from 0600 to 1200 UTC, June 2). The synoptic condition at 1200 UTC June 2, which was two hours after the beginning of the weakening stage, is shown in Fig. 10. The surface Mei-Yu front extended from Japan to the northern Taiwan Strait at 1200 UTC without frontal disturbance in the area. The pressure gradient was weak near Taiwan (Fig. 10a). Regions with a stronger height gradient at $850 \mathrm{hPa}$ were also to the north of Taiwan, and thus the west-southwesterly prevailing wind upstream was only about $5 \mathrm{~m} \mathrm{~s}^{-1}$ (Fig. 10b). At $850 \mathrm{hPa}$, flow splitting was also evident, and the wind speed reached $17 \mathrm{~m} \mathrm{~s}^{-1}$ in northern Taiwan, consistent with the formation of a barrier jet ( $\mathrm{Li}$ and Chen 1998). Thus, type $\mathrm{L}$ and $\mathrm{S}$ cases had similar synoptic setting. However, in case $\mathrm{S}$ the front did not extend into the Taiwan Strait, and the pressure gradient and wind 

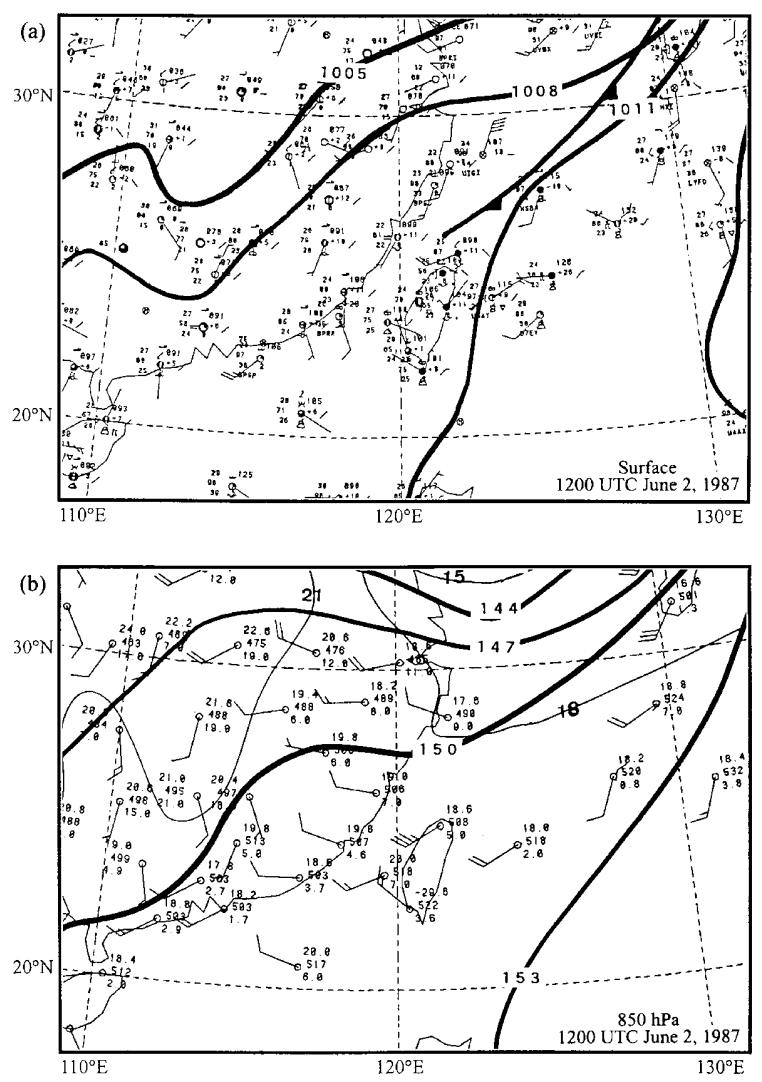

Fig. 10. Synoptic weather maps at (a) sea level, and (b) $850 \mathrm{hPa}$ for 1200 UTC, June 2, 1987. Thick solid lines are pressure $(\mathrm{hPa})$ at surface and geopotential height (dam) at $850 \mathrm{hPa}$. Thin lines are isotherms $\left({ }^{\circ} \mathrm{C}\right)$, and station plots follow meteorological convention.

speed were both weaker at the surface and $850 \mathrm{hPa}$ (Figs. 4 and 10).

\subsection{Mesoscale analyses of case evolution}

Figure 11 presents mesoscale analyses at intervals of two or three hours where appropriate. Before the intensification stage at 0000 UTC, June 2 (Fig. 11a), the surface prevailing wind was from the southwest, and flow splitting upstream from the CMR was apparent with off-shore return flow over southwestern Taiwan. A mesolow with closed isobar (with a central SLP of $\sim 1008 \mathrm{hPa}$ ) already existed along the southeast coast of Taiwan near $23.2^{\circ} \mathrm{N}$. Based on available data, however, the low possessed no closed circulation at this time, only flow with cyclonic curvature. At the windward side of the CMR, the SLP was over $1011 \mathrm{hPa}$. Therefore, a pair of mesoscale highlow couplets also appeared. A mesovortex existed along the east coast of the Hengchun Peninsula, while wind speed at Lanyu was about $10 \mathrm{~m} \mathrm{~s}^{-1}$. During the intensification stage at 0300 UTC (1100 LST, Fig. 11b) as the Mei-Yu front passed over the ocean off northern Taiwan, the prevailing wind turned westsouthwest, and the splitting of surface flow became less apparent. Winds along the southwestern coast also shifted from offshore to onshore, indicating the development of sea breeze circulation after sunrise. The offshore land breeze was also clear over the southwestern plain during previous nighttime hours (not shown). At this time, a closed circulation (mesovortex) developed near the center of mesolow to form a mesocyclone, but the vortex near Hengchun disappeared (Fig. 11b).

Figures $11 \mathrm{c}$ to $11 \mathrm{e}$ show the mesoscale analyses at 0600, 0800, and 1000 UTC June 2, as the mesolow reached the mature stage. Before 0800 UTC, the surface Mei-Yu front moved southward along the eastern coast of Taiwan, and approached the quasi-stationary mesocyclone (Figs. 11c and 11d). The front reached the Hengchun Peninsula by 1000 UTC, and the lee cyclone had merged with it and transformed into a migratory system, while another mesovortex appeared again over the Hengchun Peninsula (Fig. 11e). The prevailing wind over the Taiwan Strait also continued to shift to westerly at 0600 UTC, to northerly at 0800 UTC, and then to northeasterly at 1000 UTC. Responding to this shift, the orientation of the mesohigh-low couplet also turned from a westeast configuration to a northwest-southeast one. The southward propagation of the Mei-Yu front along eastern Taiwan in case $\mathrm{S}$ was considerably earlier than suggested by the synoptic chart, which had the front still north of Taiwan even at 1200 UTC (Fig. 10a). The mesolow reached peak intensity at 0800 UTC with a central SLP of $1006 \mathrm{hPa}$, and was recognized as a mesocyclone most of the time during the mature stage, except at 0600 UTC when the vortex center was to the north and slightly separated from the low center (Figs. 11c to 11e). In the mature stage, sea breeze was evident over the southwestern plain, and the 

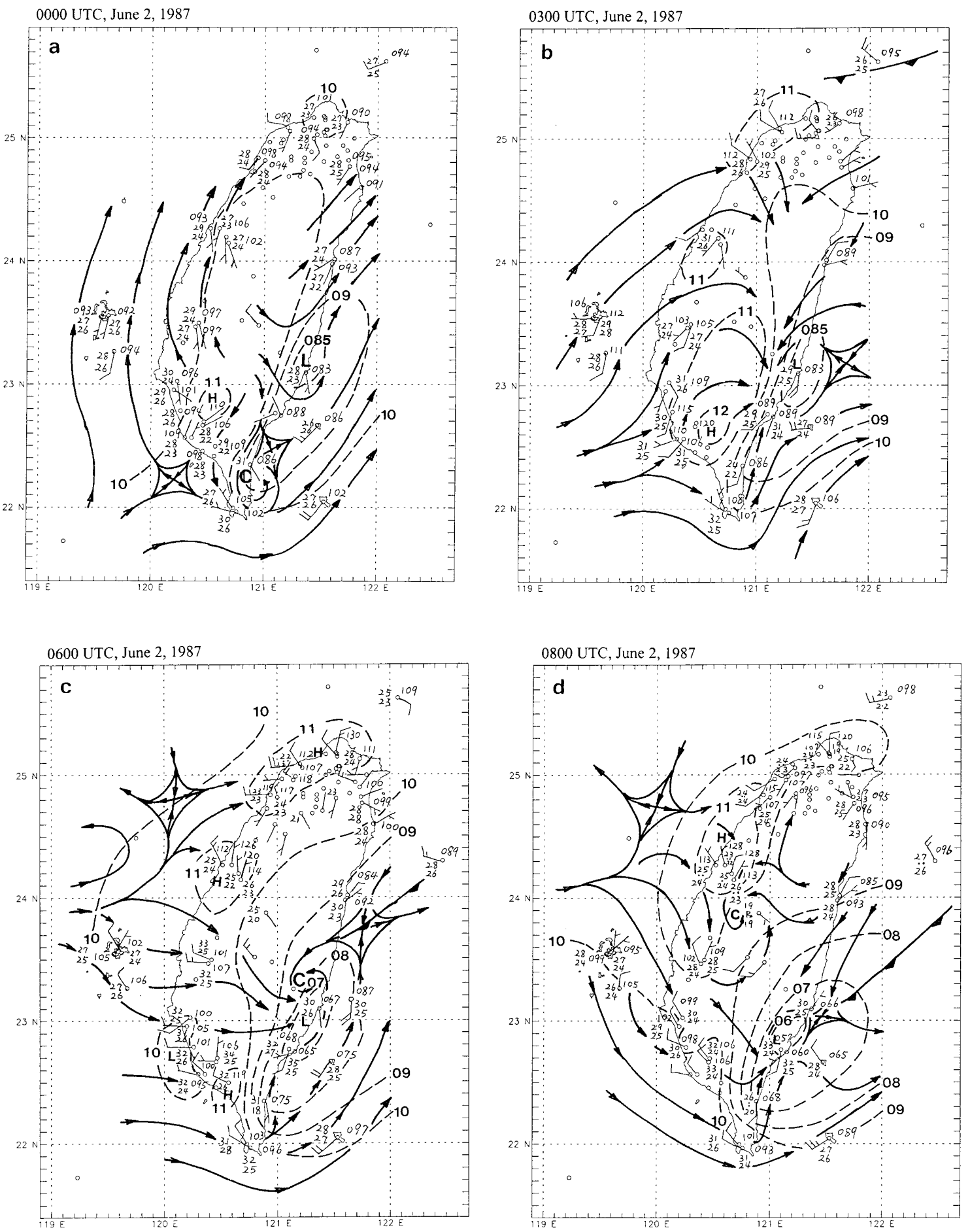

Fig. 11. Selected hourly surface mesoscale analyses of sea level pressure (dash lines, at 1-hPa intervals) and streamlines (solid lines with arrows) at (a) 0000 UTC, (b) 0300 UTC, (c) 0600 UTC, (d) 0800 UTC, (e) 1000 UTC, (f) 1200 UTC, and (g) 1500 UTC June 2, 1987. Surface fronts are also analyzed. 

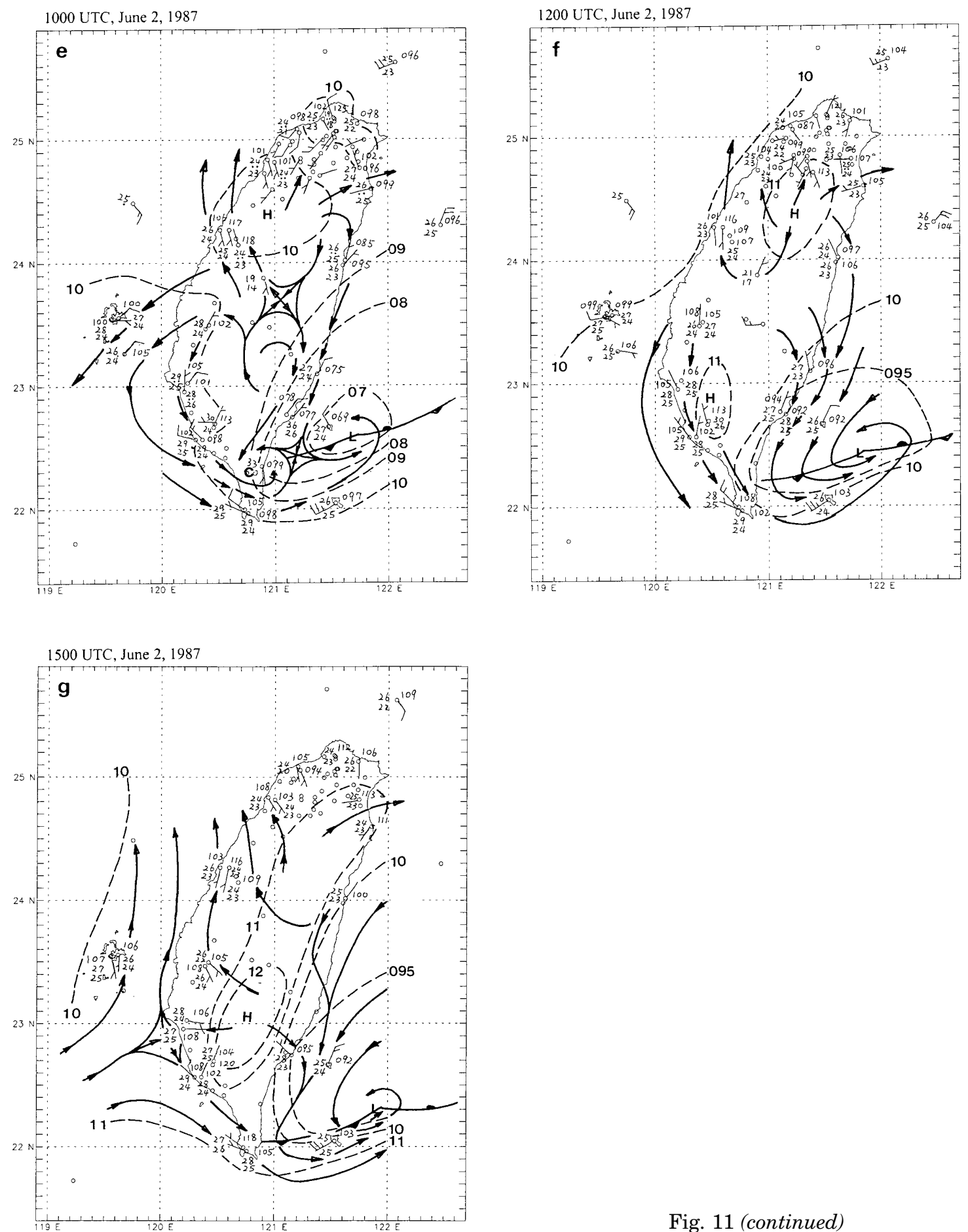

Fig. 11 (continued) 


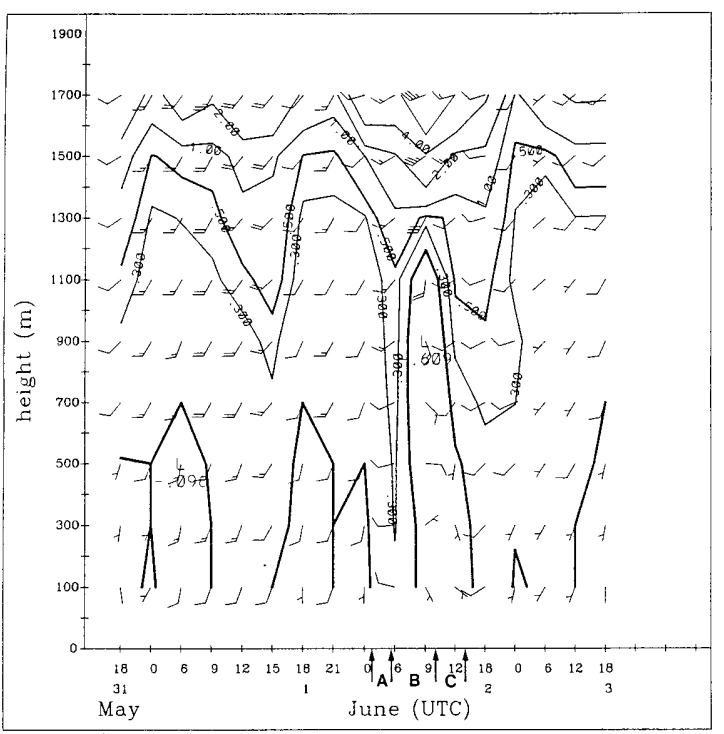

Fig. 12. Time-height cross-section of local Froude number and wind at Makung from 1800 UTC May 31 to 1800 UTC June 3, 1987. Contour line values are $0.0,0.3,0.5,1.0,2.0,4.0$, and 8.0. The letters "A", "B", and "C" denote intensification, mature, and weakening stages of case $\mathrm{S}$, respectively.

speed of west-southwesterly flow at Lanyu increased slightly to $12 \mathrm{~m} \mathrm{~s}^{-1}$.

During and shortly after the weakening stage at 1200 and 1500 UTC, the mesocyclone continued to move eastward along the Mei-Yu front to near $122^{\circ} \mathrm{E}$, gradually away from the Taiwan area (Figs. 11f and 11g). The vortex over the Hengchun Peninsula disappeared and existed only briefly. The sea breeze along the southwestern coast of Taiwan weakened markedly after sunset at 1000 and 1200 UTC (i.e., 1800 and 2000 LST, Figs. 11e and 11f), and was replaced by offshore land breeze at 1500 UTC (Fig. 11g).

\subsection{Upstream conditions}

The time-height cross-section of local $\mathrm{Fr}$ and winds at Makung (46734) is shown in Fig. 12, since data at RCJH were unavailable (Table 3). As in case L, the local $F r$ increased with height. But unlike case L, over the life span of case S the local $F r=0.5$ contour line was located between 1000 and $1300 \mathrm{~m}$ without significant change in elevation, and air parcels below this level likely lacked the kinetic energy to climb over the terrain. Below about $1200 \mathrm{~m}$, local $\mathrm{Fr}$ values reached maximum at 0600 UTC June 2, but were still less than 0.5 , when southwesterly winds of no more than $7.5 \mathrm{~m} \mathrm{~s}^{-1}$ prevailed. Afterwards, local $\mathrm{Fr}$ decreased further as the wind direction shifted below about $1100 \mathrm{~m}$ over the Taiwan Strait. The local $F r=1.0$ contour was near $1400 \mathrm{~m}$ during life stages of this case, and air above this level reached peak local $\mathrm{Fr}$ values at 0900 UTC. Therefore in case S, a considerable depth of air, below about $1200 \mathrm{~m}$, had local $F r<0.5$ and was likely blocked when encountering the terrain of Taiwan. Only a relatively shallow layer of about $400 \mathrm{~m}$ below the mountain ridge could climb over the terrain of CMR.

No significant precipitation was observed in southern Taiwan in case $\mathrm{S}$, except a light amount $\left(<15 \mathrm{~mm}\right.$ day $\left.^{-1}\right)$ at a few scattered stations along the windward side of the CMR during the mature stage (not shown). The amount of precipitation is one of the fundamental differences between the two cases selected in this study, where a substantial amount of rain fell in case $\mathrm{L}$, but almost no rain was observed in case $\mathrm{S}$.

Time-height cross-sections for the same variables as in case L were also constructed. Figure 13a shows that low-level winds below $1800 \mathrm{~m}$ were mostly from the west turning gradually to northwest upstream of the CMR during the intensification and mature stages, with a speed of about $2-5 \mathrm{~m} \mathrm{~s}^{-1}$. Winds were strong only above $2000 \mathrm{~m}$ during the case period and below that level in the weakening stage, consistent with small $F r$ values (Table 1). The appearance of northwesterly wind was most likely associated with flow deflection due to terrain blocking of the CMR, but could also be modulated by the return flow of sea breeze circulation developed on June 2. The pressure anomaly was positive everywhere during the case period at Tungkang, indicating a higher pressure at windward side as compared to the leeside (Fig. 13b). In the lower troposphere the positive anomaly grew through the intensification stage, and reached a maximum of $3.40 \mathrm{hPa}$ at $600 \mathrm{~m}, 0600$ UTC in the mature stage, then weakened afterwards. The temperature anomaly was also positive below $1000 \mathrm{~m}$, with a center of $1.77^{\circ} \mathrm{C}$ at $400 \mathrm{~m}, 0600$ UTC (1400 LST, Fig. 13c). The 

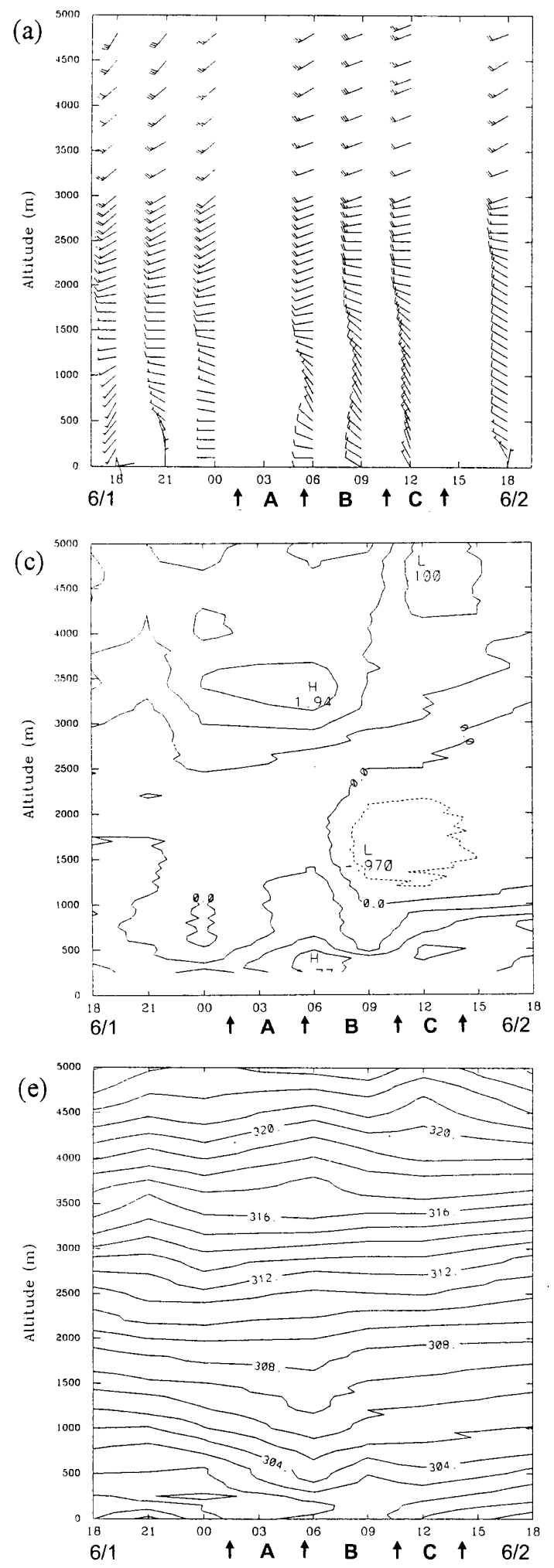
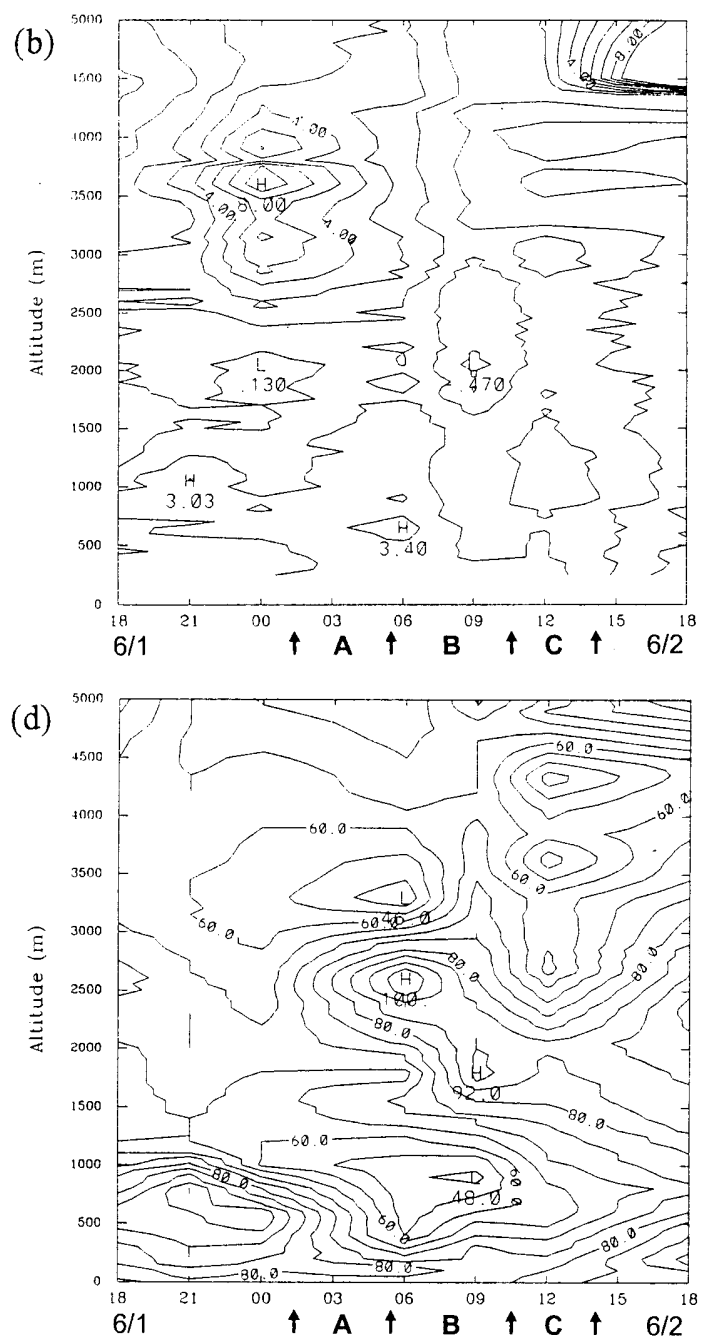

Fig. 13. Time-height cross-sections of (a) winds, (b) pressure anomaly (hPa), (c) temperature anomaly $\left({ }^{\circ} \mathrm{C}\right),(\mathrm{d})$ relative humidity, and (e) potential temperature $(\theta)$ at Tungkang station (46747) from 1800 UTC June 1 to 1800 UTC June 2, 1987. Contour intervals used in (b) to (e) are $1 \mathrm{hPa}, 0.5^{\circ} \mathrm{C}, 5 \%$, and $1 \mathrm{~K}$, respectively. Dash lines indicate negative values. Life stages $\mathrm{A}, \mathrm{B}$, and $\mathrm{C}$ of mesolow case $\mathrm{S}$ are also indicated. 
anomaly was likely caused by a stronger daytime heating within the boundary layer at Tungkang, compared to Makung and Lutao, both of which are island sites (Fig. 2). Significant cooling existed between 1000 and $2500 \mathrm{~m}$ after about $0700 \mathrm{UTC}$, and a negative center of $-0.97^{\circ} \mathrm{C}$ appeared at $1550 \mathrm{~m}$ at $0900 \mathrm{UTC}$. The altitude of this cooling agrees with the altitude of forced uplifting based on the local $\mathrm{Fr}$ analysis (Fig. 12), and was linked to adiabatic cooling at the windward side of the CMR.

Figure 13d shows the evolution of relative humidity. Below about $1000 \mathrm{~m}$, the tendency of decreasing relative humidity was evident in the intensification and mature stages, and a dry center of $48 \%$ (or $11.8^{\circ} \mathrm{C}$ of dew-point depression) was reached near $800 \mathrm{~m}$ at $0900 \mathrm{UTC}$, in agreement with the daytime warming. Above $1200 \mathrm{~m}$, relative humidity increased in the intensification and mature stages to achieve saturation near $2600 \mathrm{~m}$ at $0600 \mathrm{UTC}$ and near saturation (92\%) at about $1800 \mathrm{~m}$ at 0900 UTC. The high relative humidity centers were also consistent with adiabatic cooling associated with the rising motion. The cross-section of $\theta$ (Fig. 13e), between 200 and about $1200 \mathrm{~m}$, also reflects the diurnal cycle, with warming before 0600 UTC and cooling afterwards. The cooling further up, from 1200 to $2000 \mathrm{~m}$, after 0600 UTC was accompanied by an increase in relative humidity, and consistent with rising motion (Fig. 13e).

\subsection{Leeside response}

Time-height cross-sections for the same variables as in Fig. 13, but at Lutao (46780) on the leeside of the CMR, are shown in Fig. 14. In the lower troposphere the winds were steadily from the west-southwest to west, with a speed of 8-15 $\mathrm{m} \mathrm{s}^{-1}$, considerably stronger than those at Tungkang (Fig. 14a), unlike the situation in case L. The surface Mei-Yu front passed Lutao near 0900 UTC (cf., Fig. 11), and the cold air advection caused backing wind with height below $1200 \mathrm{~m}$ at 1200 UTC. The pressure anomaly was negative almost everywhere in the cross-section, more so below $1500 \mathrm{~m}$ (Fig. 14b). A negative center of $-6.0 \mathrm{hPa}$ was reached at $400 \mathrm{~m}$ at 0600 UTC in the mature stage, and afterwards the anomaly values weakened but were still negative. The cross-section of temperature anomaly shows significant warming extending to great depth, at least $3000 \mathrm{~m}$, during the intensification and mature stages (Fig. 14c). Two centers of positive temperature anomaly appeared at $0900 \mathrm{UTC}$, one of $2.73^{\circ} \mathrm{C}$ at $500 \mathrm{~m}$, and the other of $2.38^{\circ} \mathrm{C}$ at a much higher altitude near $1700 \mathrm{~m}$. Below $1000 \mathrm{~m}$, rapid cooling after 0900 UTC produced a negative anomaly center of $-1.93^{\circ} \mathrm{C}$ at $1200 \mathrm{UTC}$, obviously related to the cold air advection off the eastern coast of Taiwan after the passage of the Mei-Yu front.

Figure 14d shows a clear drying trend below $2500 \mathrm{~m}$ before 0900 UTC during the intensification and mature stages, most evident between 600 and $1800 \mathrm{~m}$, where a center with very low relative humidity value of less than $45 \%$ (roughly $13^{\circ} \mathrm{C}$ in dew-point temperature) was achieved. Again, such a decrease in relative humidity was caused by subsidence warming at leeside of the CMR. After the frontal passage near 0900 UTC, the relative humidity values rose rapidly below about $1000 \mathrm{~m}$ (Fig. 14d). Consistent with the trend in temperature anomaly, the $\theta$ cross-section (Fig. 14e) indicates significant warming below about $2500 \mathrm{~m}$ from the beginning to 0900 UTC near the end of the mature stage, with largest increase in $\theta$ exceeding $7 \mathrm{~K}$ near $700 \mathrm{~m}$ (over a period of $12 \mathrm{~h}$ ). The stable layer at the bottom of the sinking motion formed near $500 \mathrm{~m}$ between 0600 and 0900 UTC, suggesting that the leeside subsidence in this case reached a level even closer to the surface than in case $\mathrm{L}$. The decrease in $\theta$ values below $1000 \mathrm{~m}$ after 0900 UTC was, once again, due to the frontal passage. The leeside subsidence was also clearly indicated in timeheight cross sections of $\theta_{e}$ and specific humidity $(q)$, as both decreased in the lower atmosphere during the descending period (not shown).

\subsection{Case summary}

The type $\mathrm{S}$ case (June 2,1987) also developed when the Mei-Yu front approached Taiwan from the north, but $\mathrm{Fr}$ remained below 0.2 and did not significantly increase during its life stages. A considerable depth of low level flow (up to about $1400 \mathrm{~m}$ ) showed signs of being blocked by the CMR, and split upstream and moved around the mountain, producing higher wind speed both to the northwest and southeast of Taiwan. Air parcels above $1400 \mathrm{~m}$, with sufficient kinetic energy, rose at the windward 

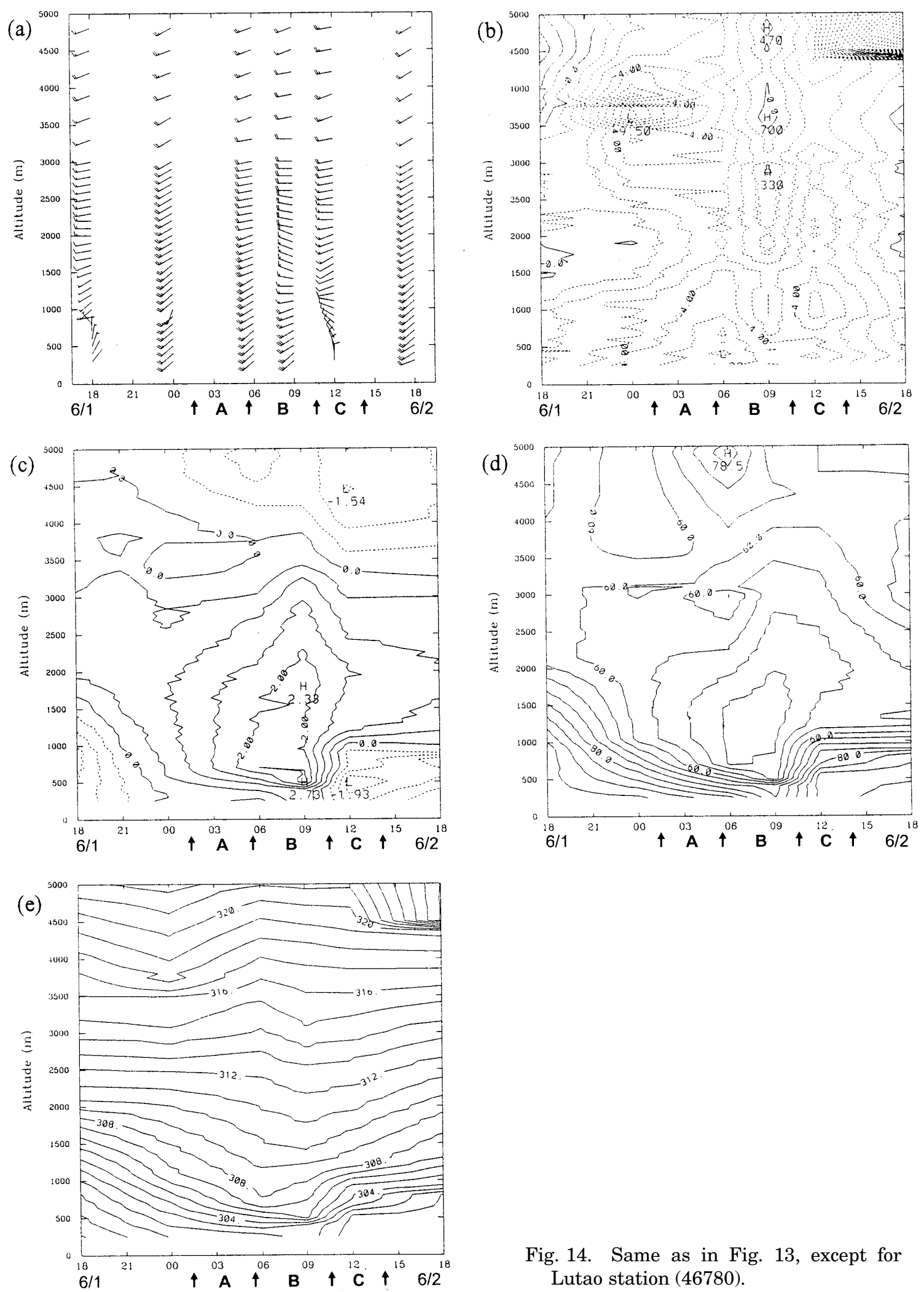

Fig. 14. Same as in Fig. 13, except for Lutao station (46780). 
side, but little precipitation occurred. Air parcels then sunk at the leeside and led to formation of mesolow through adiabatic warming. The bottom of the sinking motion, indicated by a highly stable layer, was near $500 \mathrm{~m}$, considerably lower than that in case L. The leeside mesolow, formed near $23^{\circ} \mathrm{N}$, possessed closed circulation and was recognized as a mesocyclone during most of its life span, while mesovortices also appeared rather briefly over the Hengchun Peninsula, and remained stationary. Finally, the approach of the Mei-Yu front caused the stationary mesocyclone to transform into a migratory one, then to move eastward along the front.

\section{Discussion}

\subsection{Flow structure and theoretical expectations}

Pierrehumbert (1986) has provided a thorough discussion on the pressure and wind patterns associated with flow over mountains from a theoretical perspective. Based on the linear mountain wave theory (Queney 1947; Smith 1979), for large $R o$ values ( $R o \gg 1$, and thus large $F r$ ), air flow experiences upslope deceleration and down-slope acceleration, and a pair of high-low pressure couplets is produced at the windward side and the leeside through adiabatic cooling/warming at steady state, along with upward propagating inertia-gravity waves. Since the Coriolis force is neglected, there is no cyclonic vorticity associated with the low (i.e., no lee vortex). For intermediate $R o$ values $[R o=O(1)]$, the Coriolis force becomes more significant, and the flow curves cyclonically when approaching the mountain, anticyclonically near the ridge, and cyclonically again at the leeside (Pierrehumbert 1984). The signature in the pressure pattern in this case is weak and only a vortex forms at the lee, at least at steady state. In addition, if $F r<0.5$, upstream incoming flow below the mountain top is strongly blocked. For our mesolow cases with the CMR of Taiwan, a mixture of characteristics for both $R o$ situations can be expected.

Before the steady state can be reached, there is also transient response that can be explained within the context of the quasi-geostrophic model. When a flow starts (or intensifies), the air initially at the top of the mountain is forced into the lee, and this air experiences vertical stretching and cyclonic vorticity generation without ever having been subjected to the upward anticyclonic source. Thus, a warm core cyclone is produced at the lee. For mesoscale terrain with $R o \geq O(1)$, the low is likely to form before the vortex because it requires time for the Coriolis force to generate enough vorticity. Then, geostrophic adjustment between the mass and wind fields may come into play, depending on the scale (Pierrehumbert 1986).

From Table 1 it can be seen that the $F r$, and thus $R o$, were significantly greater in case L than case S. From cross-sections of local $\mathrm{Fr}$ (Figs. 6 and 12), it can also be determined that the difference was most evident below $1400 \mathrm{~m}$. In case L, local $F r$ values between 700 and $1400 \mathrm{~m}$ increased significantly with time and exceeded 1 at late mature stage. In contrast, air below $1200 \mathrm{~m}$ had local $F r$ values less than 0.5 throughout in case S. Therefore, in case L a much thicker layer below the mountain-top level experienced forced uplift, while in case $\mathbf{S}$ most low level air was blocked by the terrain. The sounding at Jaohwa (RCJH) at 2100 UTC June 7 (Fig. 15a) suggests that the upstream air was nearly saturated below $850 \mathrm{hPa}$ and the moisture content was also high in the entire lower to middle troposphere in case L. The Makung sounding at 0600 UTC June 2, on the other hand, indicates that the lower atmosphere contained less water vapor with a somewhat higher stability at the lowest $1.5 \mathrm{~km}$ in case $\mathrm{S}$ (Fig. 15b). Thus, the difference in $\mathrm{Fr}$ between the two cases was at least partially due to their different moist stability in the upstream environment, not solely in wind speed (Table 2). This is also supported by cross sections of $\theta_{e}$ (not shown) as well as relative humidity at Tungkang, where the relative humidity was above $90 \%$ from the surface up to $5 \mathrm{~km}$ in case $\mathrm{L}$ (Fig. $8 \mathrm{~d}$ ). In case $\mathrm{S}$, however, the air had mostly drying tendency below $1400 \mathrm{~m}$, indicating no uplift, and with an initial relative humidity lower than $70 \%$ above $1400 \mathrm{~m}$, the saturation was only barely reached near $2500 \mathrm{~m}$ at 0600 UTC June 2 (Fig. 13d). Despite the difference in $\mathrm{Fr}$, however, mesolow developed in both cases. This suggests that at least two possible scenarios can occur as long as $\mathrm{Fr}$ reaches a certain value when the Mei-Yu front approaches and prevailing wind intensifies. In the case of a relatively large $F r$, the air closer to 
(a)

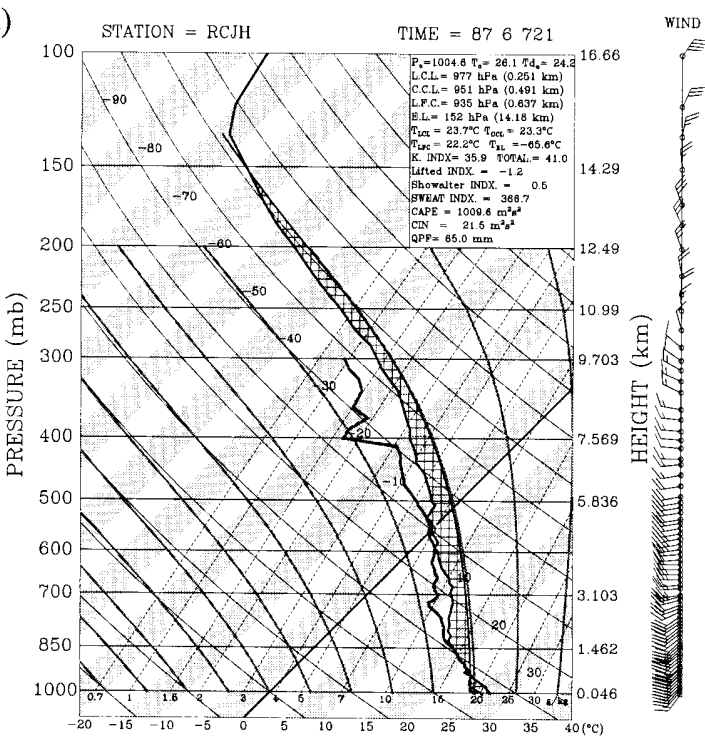

SKEW T, log P DIAGRAM

(b)

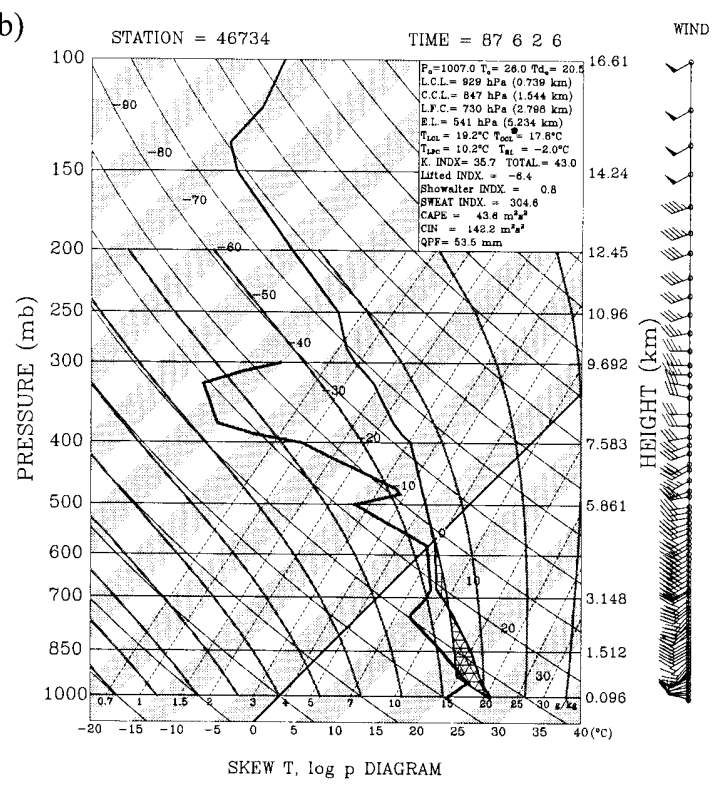

Fig. 15. Skew $T$-log $p$ diagrams at (a) Jaohwa (RCJH) at 2100 UTC June 7 , and (b) Makung (46734) at 0600 UTC June 2, 1987.

the surface with high moisture content is forced to ascent along the windward slope of the CMR and produces more precipitation, then sinks at the lee to form a mesolow, as in case L. In the second scenario with a relatively small $F r$, it is linked to $R o$ and can be explained as the following.
In case $\mathrm{L}$ where the $R o$ was larger $(R o \approx 2)$, the Coriolis force played a lesser role and this also favored the "flow-over-mountain" regime. When $R o$ is smaller $(<1)$, on the other hand, the "flow-around-mountain" scenario is enhanced due to more significant Coriolis deflection of the flow, and the upstream blocking effect is enhanced. This presence of rotation allowed the flow at higher levels to descent directly at the lee as a transient response before the low-level air could reach the lee of the mountain, as suggested by analyses of case $\mathrm{S}$. The presence of mesovortices at the lee was also quite consistent with theoretical expectations, and will be discussed shortly along with several other aspects.

\subsection{Vertical motion and leeside response}

Results of estimated vertical velocity $(\omega)$ at $850 \mathrm{hPa}$ for selected synoptic times at Tungkang and Lutao using Eq. (2) are listed in Table 4. The times selected were at the beginning of the mature stage for case L, and two hours before the intensification stage for case $S$, when leeside subsidence was significant (Figs. 9e and 14e). At Tungkang (windward side), rising motion was obtained for case $\mathrm{S}$ but sinking for case L. The sinking contradicted the expectation, and was mainly due to the substantial latent heat release, which violates the adiabatic assumption of the method. At Lutao (leeside) where the adiabatic assumption is valid, strong sinking of 0.228 and $0.213 \mathrm{~Pa} \mathrm{~s}^{-1}$ was obtained for cases $\mathrm{L}$ and $\mathrm{S}$, respectively. The two values are comparable, and their magnitude is one order greater than the effect from horizontal advection, confirming the dominant role of adiabatic subsidence in producing the mesolow. A subsidence on the order of $0.2 \mathrm{~Pa} \mathrm{~s}^{-1}$ can sink about $650 \mathrm{~m}$ in $9 \mathrm{~h}$ and produce a warming of about $2 \mathrm{~K}$, also consistent with the evolution in temperature anomaly at Lutao for both cases (Fig. 9c and 14c).

Figures $9 \mathrm{e}$ and $14 \mathrm{e}$ can also be compared directly for the strength of leeside subsidence. In case $\mathrm{L}, \theta$ values at $1200-1700 \mathrm{~m}$ increased by nearly $5 \mathrm{~K}$ in $12 \mathrm{~h}$ before $0600 \mathrm{UTC}$, June 8 (Fig. 9e), $\theta$ increase was significant at lower altitudes in case $\mathrm{S}$, by about $7 \mathrm{~K}$ at $500-1000 \mathrm{~m}$ in $12 \mathrm{~h}$ before 0600 UTC, June 2 (Fig. 14e). Thus, although $\mathrm{Fr}$ was smaller with little precipitation, the leeside sinking in case $\mathrm{S}$ was at 
Table 4. Estimated $850-\mathrm{hPa}$ vertical velocity $\left(\omega\right.$, in $\left.\mathrm{Pa} \mathrm{s}^{-1}\right)$, and various terms at 0000 UTC June 8 in case $\mathrm{L}$, and at 0000 UTC June 2, 1987 in case $\mathrm{S}$.

\begin{tabular}{lccccc}
\hline & \multicolumn{2}{c}{ Case L (0000 UTC, June 8) } & & \multicolumn{2}{c}{ Case S (0000 UTC, June 2) } \\
\cline { 2 - 3 } Parameter & Tungkang & Lutao & & Tungkang & Lutao \\
\hline \hline$\sigma\left(10^{-4} \mathrm{~K} \mathrm{~Pa}^{-1}\right)$ & 5.307 & 3.727 & 2.864 & 3.141 \\
$V_{s}(\partial T / \partial s)\left(10^{-5} \mathrm{~K} \mathrm{~s}^{-1}\right)$ & -1.500 & -0.750 & -0.750 & 0.500 \\
\hline$\omega$ from advection & -0.028 & -0.020 & -0.026 & 0.016 \\
$\omega$ from tendency & 0.079 & 0.248 & -0.011 & 0.197 \\
\hline Estimated $\omega$ & 0.051 & 0.228 & -0.037 & 0.213 \\
\hline
\end{tabular}

least comparable to that in case L. Moreover, the depth of the subsidence was indeed greater in case $\mathrm{S}$ than case $\mathrm{L}$. This is supported by the greater vertical extent of the warming and drying at Lutao, as well as by the fact that the descent penetrated a greater depth and reached a level closer to the surface in case S, when compared with case L (Figs. 9 and 13).

The SLP difference between the high-low couplets remained at $4-6 \mathrm{hPa}$ during the mature stage in both cases (Figs. 5 and 11), but the Kaoshiung minus Tungkang SLP reached a peak of about $3.7 \mathrm{hPa}$ in case $\mathrm{S}$, versus $3.0 \mathrm{hPa}$ in case $\mathrm{L}$ (Fig. 2). Therefore, all analyses indicate that the two cases were of very comparable strength, and thus a mesolow can form as long as sufficient subsidence occurs at the leeside even when $F r$ is relatively small $(\approx 0.2)$ and insufficient to produce significant uplift at the windward side of the CMR. As discussed earlier, the stronger Coriolis deflection and upstream blocking (smaller Ro) allowed the air to descent directly from levels above the mountain ridge at the lee at low $\mathrm{Fr}$ values, as exemplified in case $\mathrm{S}$ here.

\subsection{Relation to mesovortex and mesocyclone}

In both type $\mathrm{L}$ and type $\mathrm{S}$ cases, the low-level prevailing southwesterly flow split upstream of the terrain into two branches, with one to the north and the other around the southern edge of CMR to the east (Figs. 5 and 11). The northern branch produced a barrier jet along the northwestern coast of Taiwan (Chen and $\mathrm{Li}$ 1998). Through airflow confluence and acceleration, the southern branch also led to strong wind near Lanyu, reaching $20 \mathrm{~m} \mathrm{~s}^{-1}$ in case L (Fig. 5c) and about $12 \mathrm{~m} \mathrm{~s}^{-1}$ in case $\mathrm{S}$ (Fig. 11d). These LLJs provided some background shear vorticity for the development of mesoscale vortices in the region.

In cases $\mathrm{L}$ and $\mathrm{S}$, there were two favorable locations for the formation of lee vortices based on mesoscale analyses, one near the center of mesolow (north of Lutao near $23^{\circ} \mathrm{N}$ ), and the other over the Hengchun Peninsula (near $\left.120.9^{\circ} \mathrm{E}, 22.3^{\circ} \mathrm{N}\right)$. Vortices forming at the former location exhibited a closer relationship with the pressure field, and the mesolow appeared as a mesocyclone (with closed circulation), as happened in case $\mathrm{S}$ during most of its life span (Fig. 11). In case L, on the other hand, a smaller vortex formed near Hengchun, and stayed quasi-stationary until the frontal passage, such that the mesolow possessed no closed circulation most of the time (Fig. 5). The presence (or absence) of a mesocyclone in these two cases also agreed with the theoretical expectation to some extent, as at low $R o$ values the leeside wind and pressure fields should have a closer relationship, while at higher $R o$ values it is less likely for a lee vortex to form accompanying the low, as discussed in section 6a. Also, the transient effect appeared to play an important role in producing the leeside mesocyclone in case $\mathrm{S}$. Since in this case the low-level blocking was strong, and air descended directly from higher levels, little vertical compression occurred at the windward side but relatively strong stretching remained at the lee, and thus the cyclonic vorticity generation was more effective. Through numerical simulations of the TAMEX IOP-2 case, Sun and Chern (1993) suggest that the tilting and stretching effects were responsible, respectively, for the generation and amplification of 
the vertical vorticity associated with the lee vortex.

Vortices forming near Hengchun were not only smaller in size, but also highly localized, suggesting a mechanism independent from that of the mesolow. Since such a vortex was more persistent in case L where $F r$ was larger (Fig. 5 ), its formation appears to depend upon the particular shape of terrain near the Hengchun Peninsula under stronger terrain-flow interaction. Although this hypothesis appears at least plausible, at the present time the detailed formation mechanism of this localized mesovortex, and its relation to the background shear, are still unclear. Finally, in both cases the approach of the surface Mei-Yu front along the eastern coast of Taiwan provided cyclonic vorticity, and interacted with the leeside mesolow. As a result, the low merged with the front and transformed into a migratory mesocyclone along the front.

\subsection{Effect of latent heat release and precipitation}

Because of the large difference in total precipitation at the windward side between the two cases, it is expected that moist processes must have contributed differently toward raising the $\theta$ values at the leeside. Wang and Chen (2002) estimated the effect of latent heating in case L using sounding and rainfall data, and concluded that its peak contribution was about $55-60 \%$ of the total warming. In case S, however, a similar estimate would yield nearly no contribution from latent heating, since very little precipitation occurred, and thus higher $\theta$ values at the lee came almost entirely from the descent of isentropic surfaces, as discussed previously.

It is clear that the larger $\mathrm{Fr}$ in case $\mathrm{L}$ allowed moisture-rich air closer to the surface to ascend the CMR, while in case S only air farther up was able to climb over the terrain. The relatively short distance of vertical uplift in case S, and perhaps more importantly the lower initial moisture content in the air produced nearly no precipitation, and this is supported by the lower relative humidity at both the windward and the leeside (Figs. 8, 9, 13, and 14). While the increase in $\mathrm{Fr}$ in case L from 2100 UTC June 7 to 0600 UTC June 8 (Table 1) was mainly caused by a change in prevailing wind direction and speed, latent heating at the windward side, nonetheless could also play a role in lowering the stability (e.g., Durran and Klemp 1982). This reduced the blocking, and enhanced the climbing over the CMR, and further increased the difference in $\mathrm{Fr}$ between the two cases. In other words, there existed a positive feedback between $F r$ value and latent heat release in case $\mathrm{L}$, and this feedback perhaps made the difference in flow structure more apparent in the observation and the subsequent analysis between the two cases.

\section{Concluding remarks}

Based on the results found in the present study, two schematic illustrations were drawn to depict the major processes involved in the formation of leeside mesolow, and to allow easier visual comparison between the type $\mathrm{L}$ and type $\mathrm{S}$ cases (Fig. 16). The top panel (Fig.

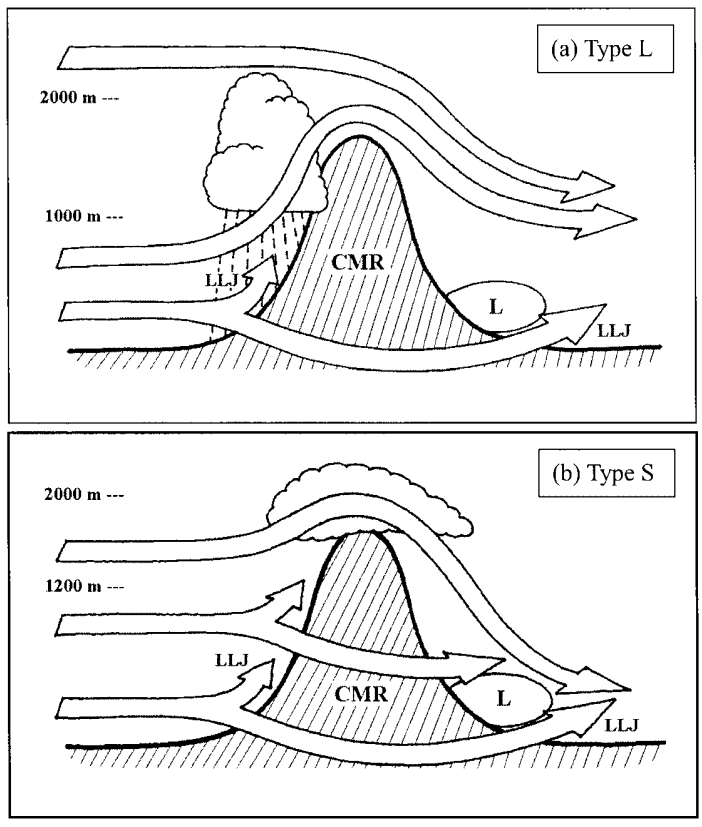

Fig. 16. Schematic illustration of processes found (a) in the type $L$ case (adopted from Wang and Chen 2002), and (b) in the type $\mathrm{S}$ case. Thick solid line and hatching represent the southern Central Mountain Range (CMR) of Taiwan, and open arrows represent trajectories of airflow at different levels. Locations of cloud, precipitation, lowlevel jet (LLJ), and leeside mesolow are also indicated. 
16a), taken from Wang and Chen (2002), illustrates the processes found in case L (type L) when both $F r$ and $R o$ were relatively large $(F r \geq 0.5, R o \geq 2.0)$. Only air at the lowest level was blocked by the CMR and split upstream, producing LLJs both to the northwest and southeast of the terrain. Flow at higher elevations (above about $800 \mathrm{~m}$ ), was forced to climb along the windward slope and produced heavy precipitation, then sunk at the leeside. Air parcels at yet higher levels above the terrain also sunk directly at the lee. The sinking led to mesolow formation through adiabatic warming, and the bottom of the sinking was near $1000 \mathrm{~m}$. In case $\mathrm{S}$ (type $\mathrm{S}$ ) when $\mathrm{Fr}$ and $R o$ were relatively small $(F r \leq 0.2, R o \leq 1.0)$, a thick layer of low level air (up to $\sim 1400 \mathrm{~m}$ ) was blocked by the CMR and also split upstream due to stronger Coriolis deflection (Fig. 16b). Air parcels above $1400 \mathrm{~m}$ rose at the windward side, but the shorter distance of uplifting and lower initial moisture content produced nearly no rain, and latent heating contributed little in raising $\theta$ values during the ascent. However, due to strong upstream blocking, air parcels sunk at the leeside directly from an elevation of about $2000 \mathrm{~m}$ to nearly $500 \mathrm{~m}$, considerably closer to the surface than that in case L.

Since the leeside sinking and mesolow produced in the two cases were of comparable strength, results suggest that as long as the Fr exceeds a certain value, both scenarios associated with relatively higher and lower $\mathrm{Fr}$ flow regime can lead to mesolow development through slightly different combinations of processes, as illustrated in Fig. 16. Also, a relatively larger $F r$ (and Ro), with windward side latent heating, does not necessarily produce a more pronounced low at the leeside, if the transient response is strong.

The magnitude of $\mathrm{Fr}$ and $\mathrm{Ro}$ also appear to affect the development of mesovortices at the leeside. Weaker flow (smaller $\mathrm{Fr}$ and $\mathrm{Ro}$ ) tends to produce mesocyclone (mesolow with closed circulation) at the lee due to stronger Coriolis and stretching effect. Stronger flow (larger $\mathrm{Fr}$ and $R o$ ), on the other hand, tends to produce small and localized vortices more independent from the mesolow, apparently due to a stronger interaction between the prevailing flow and the terrain of southern CMR. Although many conclusions in this study are drawn from only two cases, they are however in general agreement with theoretical aspects and exemplify events in the real atmosphere. Nonetheless, further investigation is suggested to substantiate these findings. Finally, the approach of the Mei-Yu front along the eastern coast of Taiwan can provide sufficient cyclonic vorticity, and cause the mesolow to transform into a migratory mesocyclone along the front in both cases.

\section{Acknowledgements}

The authors thank two anonymous reviewers for their valuable comments and suggestions, which helped to improve the manuscript. Thanks are also extended to Mr. J.S. Yang for drafting some of the figures. This study was supported by research grants NSC-91-2119-M002-029 NSC-91-2111-M-002-030 from the National Science Council of Taiwan, ROC.

\section{References}

Baines, P.G., 1995: Topographic effects in stratified flows. Cambridge Univ. Press, 482 pp.

Chen, G.T.-J., 1978: On the mesoscale systems for the Mei-Yu regime in Taiwan. Proceedings, Conference on Severe Weather in Taiwan Area, 27-28 May 1978, National Science Council, Taipei, 150-157. (in Chinese with English abstract)

, 1990: On the climatological characteristics of the mesolow in Taiwan Mei-Yu season. Atmos. Sci., 18, 73-84. (in Chinese with English abstract)

, 1991: Observational study on mesoscale features in Taiwan Mei-Yu season (I). Research Report No. NTUATM-1991-001, 136 pp. (in Chinese with English abstract)

, 1992a: Mesoscale features observed in the Taiwan Mei-Yu season. J. Meteor. Soc. Japan, 70, 497-516.

, 1992b: Observational study on mesoscale features in Taiwan Mei-Yu season (II). Research Report No. NTUATM-1992-001, 185 pp. (in Chinese with English abstract) , 1993: Observational study on mesoscale features in Taiwan Mei-Yu season (III). Research Report No. NTUATM-1993-001, 79 pp. (in Chinese with English abstract)

, 1995: Mesoscale features in the Taiwan MeiYu season: Mesolow. Atmos. Sci., 23, 1-17. (in Chinese with English abstract)

Durran, D.R. and J.B. Klemp, 1982: On the effects of moisture on the Brunt-Baisala frequency. $J$. Atmos. Sci., 39, 2152-2158.

Kuo, Y.-H. and G.T.J. Chen, 1990: The Taiwan Area 
Mesoscale Experiment (TAMEX). An Overview. Bull. Amer. Meteor. Soc., 71, 488-503.

Lalas, D.P. and F. Einaudi, 1974: On the correct use of the wet adiabatic lapse rate in stability criteria of a saturated atmosphere. J. Appl. Meteor., 13, 318-324.

Li, J. and Y.-L. Chen, 1998: Barrier jets during TAMEX. Mon. Wea. Rev., 126, 959-971.

Lin, Y.-L., N.-H. Lin, and R.P. Weglarz, 1992: Numerical modeling studies of lee mesolows, mesovortices and mesocyclones with application to the formation of Taiwan mesolows. $\mathrm{Me}$ teor. Atmos. Phys., 49, 43-67.

Pierrehumbert, R.T., 1984: Linear results on the barrier effects of mesoscale mountains. $J$. Atmos. Sci., 41, 1356-1367. , 1986: Lee cyclogenesis. Mesoscale Meteorology and Forecasting. Ed. P.S. Ray, 493-515, American Meteorological Society.

Queney, P., 1947: Theory of perturbations of stratified currents with applications to airflow over mountain barriers. Misc. Tech. Rep. 23, Dept. of Meteorology, University of Chicago.

Rotunno, R., V. Grubisic, and P.K. Smolarkiewicz, 1999: Vorticity and potential vorticity in mountain wakes. J. Atmos. Sci., 56, 2796-2810.

Smith, R.B., 1979: The influence of mountains on the atmosphere. Adv. Geophys., 21, 87-220.

- 1982: Synoptic observations and theory of orographically disturbed wind and pressure. J. Atmos. Sci., 39, 60-70.
, 1989: Hydrostatic flow over mountains. Advances in Geophysics, Vol. 31, 1-41. Academic Press.

, 1990: Why can't stably stratified air rise over high ground? Atmospheric Processes over Complex Terrain. Ed. W. Blumen, Meteorological Monographs, 23, 105-107, American Meteorological Society.

Smolarkiewicz, P.K. and R. Rotunno, 1989: Low Froude number flow past three-dimensional obstacles. Part I: Baroclinically generated lee vortices. J. Atmos. Sci., 46, 1154-1164.

Sun, W.-Y., C.-C. Wu, and W.-R. Hsu, 1991: Numerical simulation of mesoscale circulation in Taiwan and surrounding area. Mon. Wea. Rev., 119, 2558-2573. - and J.-D. Chern, 1993: Diurnal variation of lee vortices in Taiwan and the surrounding area. J. Atmos. Sci., 50, 3404-3430.

Wang, C.-C. and G.T.-J. Chen, 2002: Case study of the leeside mesolow and mesocyclone in TAMEX. Mon. Wea. Rev., 130, 2572-2592.

Wang, S.T., 1990: Subjective mesoscale analysis data during Taiwan Area Mesoscale Experiment (TAMEX). Vol. I: Original surface map collection during TAMEX Intensive Observing Periods (IOPs), $479 \mathrm{pp}$.

Wu, T.-Y. and G.T.-J. Chen, 1987: Taiwan Area Mesoscale Experiment (TAMEX). Tech. Rep. 76-19, National Science Council, ROC, 133 pp. (in Chinese with English abstract) 